\title{
PARRALES, BRACEROS Y CEPAS DE CABEZA: EL ARTE DE CULTIVAR LA VIÑA EN MENDOZA Y SAN JUAN (1561-1869)**
}

\begin{abstract}
RESUMEN
Los parrales, los braceros y las cepas de cabeza fueron las tres modalidades más utilizadas para el cultivo de la vid en Mendoza y San Juan, desde la fundación de la capital de la provincia de Cuyo del Reino de Chile por los conquistadores españoles (1561) hasta la modernización y el afrancesamiento de la viticultura argentina, en la década de 1870. El tema es relevante porque Argentina es actualmente la mayor potencia vitivinícola de América Latina y la quinta del mundo. El trabajo se ha realizado a partir de fuentes originales de los archivos de las ciudades de Mendoza, San Juan y Santiago de Chile, con el procesamiento de más de 400 mil datos sobre viñas, parrales y cepas. En el estudio se detectó que el $97 \%$ de las cepas se cultivaban en viñas y el solo $3 \%$ en parrales encatrados. Dentro de las primeras, el cultivo de las tres cuartas partes se hacía mediante el sistema en vaso, gobelet o cepas de cabeza (como se llamaba en América), mientras que el cuarto restante era embracerado: los sarmientos se conducían con varillas de sauce y álamo. Por lo general, las variedades de uva negra se cultivaban en cepas de cabeza y los moscateles en bracero o parrales encatrados.
\end{abstract}

Palabras clave: viticultura artesanal, industria vitivinícola, viñas, parrales, viticultura colonial, Mendoza, Cuyo, Santiago de Chile.

\section{ABSTRACT}

Parrales, braceros and gobelet were the three most utilized methods to cultivate grapevines in Mendoza and San Juan, since the founding of the capital of Cuyo Province in Chile's Reign. These methods prevailed from the Spanish conquest of the area, in 1561, until the impact of French-like methods in Argentina's vinegrowing in the 1870s. This topic is relevant because Argentina is today the main wine producer in Latin America and the fifth largest producer in the world. This work has been prepared based on original sources from archives located in Mendoza, San Juan and Santiago, with the processing of more than 400,000 data regarding vineyards, vines and stocks of wine. This study demonstrates that 97

* Doctor en Estudios Americanos, IDEA-USACH, y Doctor en Historia, Universidad de Buenos Aires. Profesor Titular del Instituto de Estudios Avanzados de la Universidad de Santiago de Chile. Correo electrónico: pablo.lacoste@usach.cl

** Este trabajo se ha realizado en el marco de la ejecución del proyecto FONDECYT $\mathrm{N}^{\circ}$ 1080210 . 
percent of the stocks of wine were cultivated in vineyards and only 3 percent by using parrales encatrados. Among the former, three fourths used the sistema de vaso, gobelet or cepas de cabeza, as it was called in America; The rest used an embracerado system, where vine shoots were led with willow and poplar sticks. In general, black grapes were cultivated with cepas de cabeza and muscatel wine using the bracero or parral encatrado system.

Key words: Handmade Vine-Growing, Colonial Vine-Growing, Wine Industry, Vineyards, Parrales.

Fecha de recepción: abril de 2009

Fecha de aceptación: enero de 2010

A pesar de ser una planta muy vigorosa, la vid requiere de la mano del hombre para su adecuado desarrollo. En condiciones naturales, sería una planta rastrera, por lo cual la cepa requiere del trabajo cultural que le facilite medios de sostén y conducción para alejar sus sarmientos del suelo, facilitarles el acceso al sol y promover condiciones adecuadas de crecimiento, desarrollo y fructificación.

El cultivo de la vid constituye una de las más ricas experiencias de la historia de la agricultura. Así lo determina la complejidad de los trabajos culturales que la cepa requiere durante todo el año: manejar el suelo, seleccionar los varietales, cavar, atar, podar, despampanar, binar, sostener el tronco y conducir los sarmientos. Los pueblos viticultores han tratado de develar los secretos de la viña, con un poco de teoría y mucho de ensayo, prueba y error. Y mientras el viticultor cultiva sus viñas, estas modelan su vida económica, social, cultural y hasta política. Los pueblos viticultores son diferentes ${ }^{1}$.

Los manuales de agricultura proponían recomendaciones para el manejo de las cepas. Libros españoles catalanes y franceses ofrecían criterios para seleccionar los terrenos, la variedad adecuada para cada suelo y la poda más apropiada según el caso. También entregaban información sobre los métodos de plantar la viña, cultivarla y cosecharla, para luego elaborar un buen vino ${ }^{2}$. Estos textos recomendaban las técnicas que cada autor había hallado en sus observaciones de las distintas experiencias en terreno, pero había discrepancias entre unos y otros. Paralelamente, desde el siglo XI, los cabildos impulsaron ordenanzas que regulaban el cultivo de la viña, incluyendo normas sobre datas de fin de cosecha, linderos, salarios, precios y algunas tareas culturales. Sin embargo, a lo largo de los siglos convivieron distintos

Fernand Braudel, La identidad de Francia, Barcelona, Gedisa, 1993.

2 Gabriel Alonso Herrera, Agricultura General [1513], Madrid, Imprenta Real, 1818; Miguel Agustí, Libro de los secretos de agricultura, casa de campo y pastoril [1617], Barcelona, Imprenta de Juan Piferrer, 1722; Jean Baptiste Francois Rozier, Cours complet d'agriculture théorique, pratique, économique, et de médecine rurale et vétérinaire; suivi d'une Méthode pour étudier l'agriculture par principes: ou Dictionnaire universel d'agriculture, París, Rue et Hôtel Serpente, (Imprenta Marchant, et Cl. Simon), 1781-1800; Antoine Cadet de Vaux, Instruction sur l'art de faire le vin, París, Agasee, 1800 [edición en español: Arte de hacer el vino, traducción de Manuel Pedro Sánchez Salvador y Berrio, Pamplona, Imprenta de la viuda de Longás e hijo, 1803]; Jean-Antoine Chaptal, François 
modos de cultivar la vid según las tradiciones locales. Con relativa independencia de las recomendaciones teóricas, los viticultores transitaron sus propios caminos, en busca de una identidad y un estilo. El desarrollo de esta multiplicidad de experiencias se produjo, principalmente, en la vitivinicultura artesanal.

La etapa artesanal de la viticultura americana se extendió desde los orígenes de la colonización española hasta mediados del siglo XIX. A partir de entonces, el proceso de modernización produjo cambios profundos en el tipo de varietal, el modo de cultivar la viña, elaborar, transportar y comercializar el vino. Las cepas francesas reemplazaron a las españolas y criollas, mientras que el alambre se convertía en el eje de los sistemas de conducción. Las instalaciones y el equipamiento de las bodegas priorizaban bienes importados de Francia. En la dirección técnica, los enólogos profesionales desplazaron a los intuitivos para imponer los métodos "políticamente correctos". Y en el transporte, los ferrocarriles ocuparon el lugar de carretas y mulas. En pocas décadas se produjo un cambio profundo, que vino a alterar un modo de producción que se había mantenido durante tres siglos.

Con los nuevos medios y métodos se generó un fuerte incremento en la producción de uva y elaboración de vino. En el siglo XX se produjo una notable expansión de todo el sistema productivo. En algunos países latinoamericanos, y particularmente en Argentina, se levantaron grandes fábricas de vino, capaces de inundar el mercado. Mientras en Europa se procuró mantener la pequeña propiedad vitivinícola, en el sur de América se avanzó en la dirección contraria. Allí se rompió el tradicional lazo de la viticultura con la pequeña propiedad, para abrir el camino a grandes paños de más de 3 mil hectáreas de viña, cifra que tradicionalmente podían alcanzar los cultivos extensivos de cereales, pero jamás los viñedos. Se batieron todos los récords de quintales de uva cosechada y hectolitros de vino elaborado. La industria vitivinícola creció hasta niveles insospechados. En el siglo XX, Argentina se convirtió en el mayor productor vitivinícola de América Latina y el cuarto del mundo ${ }^{3}$. En una temporada llegó a instalarse en el tercer puesto, desplazando transitoriamente a España ${ }^{4}$, pero luego volvió a su tradicional cuarto lugar, posi-

Rozier y Antoine Parmentier, Traité théorique et pratique sur la Culture de la Vigne, avec l'Art de Faire le Vin, les Eaux-de-Vie, Esprit-de-Vin, Vinaigres simples et composés, Ouvrage dans lequel se trouvent les meilleurs méthodes pour faire, gouverner et perfectionner les Vins et Eaux-de-Vie, París, Delalain, 1801, 2 vols; Marquis de Travanet, Rudiment agricole universel par demandes et par réponses, ou l'agriculture enseignée par ses principes applicables à sa pratique en tous lieux, París, Mme Huzard, 1845 [edición española: Catecismo de Agricultura, o sea la agricultura enseñada por principios aplicados a la práctica de todos los lugares, traducción de Pedro Martín de López, Madrid, Imprenta de Santiago Saunaque, 1848; Antonio Sandalio Arias, Novísima agricultura práctica o sea, manual del labrador, hortelano, jardinero y arbolista según los adelantos del día y la práctica de los más célebres agricultores nacionales y extranjeros, Madrid, Al libro de oro, 1856; Jules Guyot, Étude des vignobles de France pour servir à l'enseignement mutuel de la viticulture et de la vinification francaises, París, Imprimerie Impériale, 1868, 3 vols.

3 En la década de 1960 Argentina elaboró alrededor de 20 millones de hectolitros anuales, lo cual le permitió posicionarse como el cuarto mayor productor mundial de vinos, debajo de Francia, Italia y España. Instituto Nacional de Vitivinicultura, Síntesis de Estadística Vitivinícola 1963, Mendoza, INV, 1964, 4; Síntesis de Estadística Vitivinícola 1965, 5; y Estadística Vitivinícola 1968, 7.

4 En 1967 Argentina superó a España al elaborar 28.170 mil hl contra 22.660 de los españoles (Estadística Vitivinícola 1968, 7). 
ción que mantuvo hasta $1990^{5}$. En ese momento se produjo una fuerte crisis en la viticultura argentina, cuya producción cayó de 20 a 13 millones de hl anuales. Poco después inició un proceso de recuperación y transformación, con la idea de mejorar la calidad e iniciar las exportaciones, lo que le permitió encontrar un nuevo punto de equilibro, alrededor de los 15 millones de hl, pero en el intertanto ya había retrocedido un puesto en la escala, al ser superada por EE.UU. Entre 1990 y 2006, Argentina se mantuvo como el quinto productor mundial de vinos ${ }^{6}$.

La estandarización y el aumento cuantitativo de la producción no tardaron en generar problemas de superproducción, caídas de precios y crisis cíclicas de la industria, pero, sobre todo, se produjo un problema de crisis de identidad del vino como producto artesanal. En muchos casos, el vino pasó a operar como mero commodity, un producto de calidad estandarizada, de escaso valor y bajo precio. Para completar el cuadro, Argentina demoró indefinidamente la ley de envasado en origen. A lo largo de casi todo el siglo XX, los vinos se elaboraban en Cuyo, se trasladaban a granel hasta los lugares de consumo (Buenos Aires principalmente) y allí se envasaban. Esta situación, intrínsecamente inadecuada, se agravó todavía más, con estiramientos y fraudes, y la mentira nunca deja de generar pérdida de confianza en el cliente y pérdida del valor en el producto. Durante largas décadas, la viticultura argentina estuvo a la deriva, en un contexto de leyes más propias de una industria en serie -sin identidad ni personalidad-, que de la delicada industria del vino. Ello condujo a la crisis de la industria vitivinícola argentina de la década de 1980 , proceso que se comenzó a revertir hace poco tiempo, con la reconversión de la actividad, la caída de las grandes fábricas de vino y la recuperación de la viticultura de calidad, las llamadas "bodegas boutique" y las exportaciones de vinos de alto nivel.

Naturalmente, hubo también grupos de viticultores que se resistieron a perder la identidad tradicional y, a pesar de las tendencias de los grandes mercados, trataron de mantener sus formas particulares de cultivar las plantas y elaborar el vino, con el cuidado de la Edad Media europea o la Colonia americana. Siguiendo este método, algunos viticultores no alcanzaron la rentabilidad requerida y desaparecieron. Otros lograron adaptarse a las circunstancias, a la vez que preservaron su identidad, y se mantuvieron hasta la actualidad. Pero ese tema escapa a los alcances del presente artículo.

El objetivo de este trabajo es examinar la forma de cultivar la vid durante la etapa artesanal en Mendoza y San Juan. Se trata de una región relevante, porque actualmente constituye la mayor potencia vitivinícola de América Latina y la quinta del mundo. Este espacio se hizo conocido desde fines del siglo XIX, por la concurrencia de los ferrocarriles ingleses y los inmigrantes europeos, que impulsaron un acelerado

\footnotetext{
5 En el quinquenio 1986-1990, Argentina elaboró 19,9 millones de hl de vino, lo cual le permitió mantener el cuarto nivel mundial.

6 Organización Internacional de la Vid y el Vino, Estadísticas Vitivinícolas Mundiales, página 11, Tabla 4, "Principales países productores de vino (1986-2006)", disponible en http://news.reseauconcept.net/images/oiv_es/Client/Commentaire_statistiques_annexes_2006_ES.pdf
} 
y exitoso proceso de modernización. Esas historias son bien conocidas, debido a la amplia bibliografía que se ha ocupado de ella. Sin embargo, hasta ahora muy poco se conoce de la etapa tradicional de esta región: la que se extiende desde la fundación de la ciudad de Mendoza por parte de los españoles (1561) hasta la llegada de los factores de modernización a partir de la década de $1870^{7}$.

Durante más de trescientos años, la viticultura artesanal se mantuvo bastante igual a sí misma en muchos aspectos: los medios de transporte fueron los arrieros de mulas y los troperos de carretas; la ausencia de alambres planteaba desafíos para la conducción de los sarmientos; y las dificultades para acceder a los manuales de agricultura y la ausencia de enólogos profesionales determinaban la importancia de la intuición, el método de ensayo y error, y el surgimiento natural de clusters, en donde los viticultores autodidactas podían compartir sus secretos.

La literatura especializada, hasta ahora, ha construido un discurso negativo y pobre sobre el valor de la viticultura artesanal en Cuyo. Los autores se han inclinado a destacar las debilidades y falencias de los modos de cultivar la vid antes de la modernización. Luque (1959) y Vega (1962) tendieron a asociar los cultivos tradicionales con el atraso y la falta de calidad, destacando que solo los nuevos métodos, basados en los alambres, ofrecían perspectivas positivas y de calidad, criterios que se reflejan también en los textos de Marianetti (1965), Reina Rutini (1985, 1994) y Coria (1988). Las descripciones de estos autores, basadas principalmente en observaciones contemporáneas y tradiciones orales, serán confrontadas con los documentos originales de los archivos.

Para obtener resultados que sean lo más representativos posible, conviene examinar muestras que abarquen las dos épocas (colonial e independiente) y emprendimientos vitivinícolas de distintas dimensiones (grandes, medianos, pequeños y micro). Es necesario estar atentos a las descripciones de las viñas, para incluir tanto los datos que se acerquen a las descripciones de Marianetti, como los que se alejan de ellas, con la idea de alcanzar conclusiones generales, con sus correspondientes matices.

Las fuentes disponibles para conocer los viñedos cuyanos son los registros que, en su momento, se realizaron por motivos comerciales, económicos y jurídicos. Se trata de los contratos de compraventa, testamentos, cartas de dote, tasaciones, inventarios de bienes y demás protocolos que levantaron los escribanos, jueces y partes interesadas. Estos documentos comenzaron a producirse casi inmediatamente después de la llegada de los españoles a Cuyo y con el correr de los años se formó un corpus documental de dimensiones considerables. Esta documentación se encuentra en el Archivo Histórico de Mendoza y en los dos archivos de San Juan (Archivo General de San Juan y Archivo del Poder Judicial de San Juan). Algunas ramificaciones de los expedientes se encuentran también en el Archivo Nacional de Chile y en el Archivo General de la Nación (Buenos Aires), entre otros.

\footnotetext{
7 En los últimos años se han realizado importantes avances en el estudio de la historia vitivinícola colonial latinoamericana. Se han examinado aspectos políticos, económicos, sociales y culturales de las comunidades centradas en la industria del vino. Sin embargo, todavía no se han realizado estudios focalizados, específicamente, en el tipo de uva y la forma de cultivar la viña.
} 
En el desarrollo de la investigación se registraron esos archivos, donde se encontraron datos de interés para los siglos XVI y XVII. Fue la etapa de introducción de las plantas europeas y su adaptación a los climas y suelos cuyanos. En general, los viticultores cuyanos se dedicaron a aprender las técnicas más adecuadas para cultivar esas plantas en esos terrenos. No fue posible, todavía, desarrollar modalidades complejas ni definidas de viticultura. Al menos eso dicen las fuentes: se limitan a mencionar la existencia de viñas y cepas, sin dar cuenta de datos específicos sobre medios de sostén y de conducción, podas y prácticas culturales. Esta situación comenzó a variar en la primera mitad del siglo XVIII, con el inicio de los cultivos en parrales, el uso de rodrigones y, en algunos casos, de sistemas de conducción. Este proceso logró avanzar en la segunda mitad de esa centuria, para alcanzar su plenitud en la etapa siguiente: los dos primeros tercios del siglo XIX fueron el ciclo culminante de la viticultura artesanal. Las fuentes registraron con precisión las modalidades y prácticas usadas para el cultivo de las viñas y parrales. Hay datos cualitativos y cuantitativos y se entrega, incluso, información sobre los materiales usados para horcones, tutores y braceros.

La producción de los registros se vio impulsada por el Estado. Con vistas a organizar sistemas de impuestos y contribuciones, se dispuso el levantamiento de una serie de padrones, a partir de los cuales, se elaboraron listas de viticultores. Los tres relevamientos principales fueron el padrón de propietarios de Mendoza (1739), el censo de bodegueros de San Juan (1773-1776) y el censo de viñedos Mendoza $(1825)^{8}$. Estos registros no entregan detalles de las viñas, pero significan un avance importante, al brindar el listado de viticultores. El padrón de 1739 detectó 150 vecinos propietarios en Mendoza, de los cuales 96 cultivaban viñas; el censo de bodegueros de San Juan de la década de 1770 registró 81 casos; y medio siglo más tarde, el censo de 1825 identificó 362 viticultores en Mendoza. Sobre la base de esas nóminas, el camino fue revisar las descripciones específicas de esas propiedades, en la documentación de archivo. Se han revisado registros notariales y expedientes judiciales, sobre todo inventarios de bienes y tasaciones. Naturalmente, no se levantaron inventarios detallados de los bienes de todos los viticultores. Asimismo, dentro de los que fueron relevados, no siempre se realizaron registros precisos sobre la forma de cultivar la viña y las variedades de uva. La mayor parte de las veces, los documentos se limitaron a mencionar la existencia de viñas, sin aclarar la forma de cultivo. Estos datos se registraron en pequeño porcentaje, por lo que fue preciso realizar una búsqueda notablemente lenta para obtenerlos, dentro de una masa documental muy amplia. Finalmente se logró el objetivo: se detectaron los detalles buscados en las haciendas de 22 viticultores del padrón de 1739, 25 del censo de bodegueros de San Juan de 1773-76 y 72 del censo de 1825

8 Padrón de 1739: Publicado en Revista de la Junta de Estudios Históricos de Mendoza 2, Mendoza, 1936, 259-266; y en Luis Alberto Coria, Evolución económica de Mendoza en la época colonial, Mendoza, Universidad Nacional de Cuyo, 1989, anexo 7, 295-303. Censo de viñedos 1825, Cálculo del capital que se considera en el ramo de viñas de esta provincia formado en enero de 1825 , Archivo Histórico de Mendoza (en adelante AHM), Carpeta $\mathrm{N}^{\circ} 343$, época Independiente, documento $\mathrm{N}^{\circ}$ 4, Manuales de Aduana, años 1823-1830. 


\section{CUADRO I}

\section{MODO DE CULTIVAR LA VIÑA EN MENDOZA. DESCRIPCIÓN GENERAL A PARTIR DE LA LISTA DE LOS VITICULTORES REGISTRADOS EN EL PADRÓN DE 1825 Y SU EVOLUCIÓN(MENDOZA, 1812-1866)}

\begin{tabular}{|c|c|c|c|c|c|c|}
\hline & \multirow{2}{*}{$\begin{array}{l}\text { Tasación censal } \\
\text { (en pesos) } \\
\text { Todos } \\
\text { corresponden } \\
\text { al año } 1825\end{array}$} & \multicolumn{2}{|c|}{$\begin{array}{c}\text { Tasación notarial } \\
\text { (en pesos) }\end{array}$} & \multicolumn{3}{|c|}{ Modo de cultivo } \\
\hline & & $\begin{array}{l}\text { Valor } \\
\text { tasación }\end{array}$ & Año & $\begin{array}{l}\text { Viña de } \\
\text { bracero }\end{array}$ & $\begin{array}{l}\text { Viña de } \\
\text { cabeza }\end{array}$ & Parral \\
\hline GRANDES & & +30.000 & & 15.238 & 52.772 & 824 \\
\hline 1- José Albino Gutiérrez & 9.000 & 118.500 & 1831 & 1.837 & 1.198 & 15 \\
\hline 2- José Vicente Zapata* & 4.000 & 93.000 & 1851 & 252 & 7.513 & 0 \\
\hline 3- José María Videla & 12.000 & 63.000 & 1863 & 3.593 & 0 & 206 \\
\hline 4- Manuel Peralta & NO FIGURA & 47.500 & 1824 & 340 & 0 & 304 \\
\hline 5- José Clemente Benegas & 7.100 & 35.700 & 1835 & 211 & 5.525 & 25 \\
\hline 6- José Díaz Barroso & NO FIGURA & 34.500 & 1822 & 3.393 & 4.265 & 0 \\
\hline 7- María Lorenza Moyano & 5.200 & 32.200 & 1848 & 1.360 & 4.933 & 274 \\
\hline 8- Francisco Borja Godoy & 4.000 & 31.200 & 1852 & 48 & 6.669 & 0 \\
\hline 9- Melchor Molina & 6.500 & 30.000 & 1831 & 204 & 7.281 & 0 \\
\hline 10- Manuel Ignacio Molina & 10.600 & 30.100 & 1829 & 4.000 & 15.388 & 0 \\
\hline MEDIANOS & & $-30 / 10.000$ & & 10.974 & 51.453 & 2.934 \\
\hline 11- José Godoy & 5.000 & 28.000 & 1845 & 544 & 153 & 0 \\
\hline 12- Juan José Lemos & 8.100 & 25.600 & 1843 & 1.620 & 4.027 & 1.620 \\
\hline 13- Juan Agustín Videla & 3.500 & 25.000 & 1845 & 261 & 1.072 & 69 \\
\hline 14- Manuel José García & 3.000 & 22.700 & 1838 & 2.300 & 0 & 143 \\
\hline 15- Juan Simeón Moyano & 13.000 & 21.500 & 1835 & 1.738 & 0 & 15 \\
\hline 16- Bernardino Morales & NO FIGURA & 20.800 & 1835 & 376 & 3.560 & 492 \\
\hline 17- Vicente Pescara** & 2.500 & 19.000 & 1840 & 963 & 0 & 0 \\
\hline 18- Bernardo Álvarez & s/ capital & 17.500 & 1861 & 0 & 0 & 561 \\
\hline 19- Carmen Almandos & NO FIGURA & 17.000 & 1828 & 420 & 6.000 & 0 \\
\hline 20- Benito Segura & 8.000 & 16.300 & 1848 & 0 & 5.356 & 0 \\
\hline 21- María Francisca Pelliza & 1.300 & 16.100 & 1846 & 1.252 & 6.036 & 21 \\
\hline 22- Carmen Correa & 7.000 & 15.500 & 1827 & 72 & 4.603 & 0 \\
\hline 23- Candelaria Vargas & 4.000 & 15.200 & 1821 & 814 & 0 & 0 \\
\hline 24- Juan Isidro Maza & & & 1854 & 0 & 7.632 & 13 \\
\hline 25- Francisco Coria & 3.400 & 12.400 & 1830 & 430 & 8.105 & 0 \\
\hline 26- Juan Jordán & 100 & 12.000 & 1826 & 184 & 1.500 & 0 \\
\hline 27- Vicente Torres & 4.000 & $\mathrm{~S} / \mathrm{d}$ & 1833 & 0 & 3.409 & 0 \\
\hline
\end{tabular}

\footnotetext{
* José Vicente Zapata, en el registro de 1863, subió de 252 a 494 cepas de bracero.

** En 1813 Margarita Medina cultivaba 1.963 cepas en bracero y 6 en parral encatrado. Después de su fallecimiento, quedó al mando de esta propiedad su marido, Vicente Pescara. Su gestión no fue capaz de mantener lo que ella tenía. En los registros de 1840 sus viñas apenas tenían 963 cepas en bracero y ya no estaban los parrales encatrados. En este cuadro no se ha computado el dato de Margarita sino el de su marido.
} 


\begin{tabular}{|c|c|c|c|c|c|c|}
\hline & \multirow{2}{*}{$\begin{array}{c}\text { Tasación censal } \\
\text { (en pesos) } \\
\text { Todos } \\
\text { corresponden } \\
\text { al año } 1825 \\
\end{array}$} & \multicolumn{2}{|c|}{$\begin{array}{c}\text { Tasación notarial } \\
\text { (en pesos) }\end{array}$} & \multicolumn{3}{|c|}{ Modo de cultivo } \\
\hline & & $\begin{array}{l}\text { Valor } \\
\text { tasación }\end{array}$ & Año & $\begin{array}{l}\text { Viña de } \\
\text { bracero }\end{array}$ & $\begin{array}{l}\text { Viña de } \\
\text { cabeza }\end{array}$ & Parral \\
\hline PEQUEÑOS & & -10.000 & & 12.126 & 23.397 & 1.669 \\
\hline 28- Juan Antonio Chavarrieta & NO FIGURA & 8.500 & 1826 & 2 & 4 & 0 \\
\hline 29- Felipe Segura & 2.000 & 7.600 & 1836 & 0 & 1.302 & 0 \\
\hline 30- José María Baro & 900 & 7.500 & 1864 & 0 & 4.280 & 208 \\
\hline 31- Domingo Funes & s/ capital & 7.400 & 1834 & 1.008 & 0 & 0 \\
\hline 32- Domingo Coria & 500 & 7.200 & 1839 & 1.241 & 0 & 7 \\
\hline 33- José Manuel Funes & 800 & 7.100 & 1853 & 511 & 1.470 & 349 \\
\hline 34- Francisco Guiñazú & 500 & 6.800 & 1845 & 454 & 3.520 & 0 \\
\hline 35- Juan Videla & 5.900 & s/ datos & 1854 & 189 & 2.387 & 11 \\
\hline 36- María Josefa Moyano & NO FIGURA & 5.200 & 1845 & 56 & 0 & 0 \\
\hline 37- Eduardo Larreta & 4.000 & 5.000 & 1861 & 376 & 3.782 & 510 \\
\hline 38- Manuel Silvestre Videla & 2.000 & 4.900 & 1854 & 3.206 & 385 & 0 \\
\hline 39- Lorenzo Guevara & 1.300 & 4.600 & 1834 & 105 & 154 & 0 \\
\hline 40- Damián Carrión & s/ capital & 4.600 & 1834 & 0 & 0 & 84 \\
\hline 41- Pedro Valderrama & 1.000 & 4.500 & 1847 & 112 & 2.787 & 0 \\
\hline 42- José Vicencio Vargas & 800 & 3.800 & 1825 & 96 & 0 & 0 \\
\hline 43- Ma. Dominga Quevedo & 1.000 & 3.500 & 1835 & 2.001 & 173 & 0 \\
\hline 44- Eduardo Valenzuela & NO FIGURA & 3.500 & 1826 & 41 & 0 & 0 \\
\hline 45- Jacinto Godoy & 8.000 & 3.300 & 1850 & 5 & 0 & 0 \\
\hline 46- Francisca Puebla & s/ capital & 3.200 & 1825 & 244 & 0 & 0 \\
\hline 47- Marcos González & s/ capital & 2.900 & 1850 & 256 & 0 & 0 \\
\hline 48- Domingo Puebla & s/capital & 2.500 & 1812 & 43 & 0 & 0 \\
\hline 49- Nazario Gómez & 1.000 & 2.200 & 1834 & 905 & 0 & 0 \\
\hline 50- Pedro Carrera & 800 & 2.100 & 1827 & 0 & 0 & 287 \\
\hline 51- Ignacio Silva & s/ capital & 2.000 & 1840 & 62 & 520 & 0 \\
\hline 52- Lugarda Pereyra & s/ capital & 1.100 & 1849 & 0 & 2.242 & 13 \\
\hline 53- Pedro Rodríguez & s/ capital & 1.100 & 1813 & 737 & 0 & 0 \\
\hline 54- Juan Godoy & s/ capital & 1.000 & 1844 & 179 & 261 & 0 \\
\hline 55- José Ríos & 500 & 900 & 1866 & 297 & 130 & 0 \\
\hline 56- Juan Valenzuela & 500 & $\mathrm{~S} / \mathrm{D}$ & 1827 & 0 & 0 & 200 \\
\hline Total general & & & & 39.301 & 127.622 & 5.427 \\
\hline
\end{tabular}

Fuente: Archivo Histórico de Mendoza. Época Independiente. Sección Judicial. Testamentarias. 
en Mendoza. A ello se sumaron otros 10 casos correspondientes a los viticultores de San Juan para el segundo tercio del siglo XIX. En total se han reunido descripciones de los bienes de 129 viticultores cuyanos y, sobre esta base, se ha constituido un corpus documental de más de 2 mil páginas con cerca de 400 mil datos sobre la forma de cultivarlas. Se han compulsado estas fuentes a la luz de las descripciones de Luque, Vega, Marianetti, Reina Rutini y Coria.

\section{CUADRO II}

\section{MODO DE CULTIVAR LA VIÑA EN MENDOZA. ANÁLISIS DE LOS VITICULTORES REGISTRADOS EN EL PADRÓN DE 1825 Y SU EVOLUCIÓN. DISCRIMINACIÓN POR TAMAÑO DE LAS PROPIEDADES (MENDOZA, 1812-1866)}

\begin{tabular}{|c|c|c|c|c|c|c|c|c|}
\hline \multirow{3}{*}{$\begin{array}{l}\text { UNIDAD } \\
\text { PRODUCTIVA } \\
\text { POR TAMAÑO }\end{array}$} & \multicolumn{4}{|c|}{ VIÑAS } & \multicolumn{2}{|c|}{ PARRALES } & \multicolumn{2}{|c|}{ TOTAL } \\
\hline & \multicolumn{2}{|c|}{$\begin{array}{l}\text { Con conducción: } \\
\text { cepa de bracero }\end{array}$} & \multicolumn{2}{|c|}{$\begin{array}{c}\text { Sin conducción: } \\
\text { cepa de cabeza }\end{array}$} & \multirow[b]{2}{*}{$\begin{array}{l}\text { Cantidad } \\
\text { plantas }\end{array}$} & \multirow[b]{2}{*}{$\%$} & \multirow[b]{2}{*}{$\begin{array}{c}\text { Cantidad } \\
\text { plantas }\end{array}$} & \multirow[b]{2}{*}{$\%$} \\
\hline & $\begin{array}{l}\text { Cantidad } \\
\text { plantas }\end{array}$ & $\%$ & $\begin{array}{c}\text { Cantidad } \\
\text { plantas }\end{array}$ & $\%$ & & & & \\
\hline GRANDES +\$30.000 & 15.238 & 22,1 & 52.772 & 76,7 & 826 & 1,2 & 68.836 & 100 \\
\hline MEDIANAS \$29 a $\$ 11.000$ & 11.937 & 18,0 & 51.453 & 77,6 & 2.934 & 4,4 & 66.324 & 100 \\
\hline PEQUEÑAS -\$10.000 & 12.126 & 32,6 & 23.397 & 62,9 & 1.669 & 4,5 & 37.192 & 100 \\
\hline Total general & 39.301 & 22,8 & 127.622 & 74,0 & 5.429 & 3,2 & 172.352 & 100 \\
\hline
\end{tabular}

Con respecto a las unidades de valor monetario usadas en el texto, lo más importante es indicar que se emplea el peso de a ocho reales, implementado por la corona de España en Indias, y que sobrevivió varias décadas después de la Independencia, al menos en el área estudiada.

\section{LA FORMA DE CULTIVAR LA VIÑA EN CUYO}

El análisis de la viticultura tradicional en Cuyo debe comenzar en el lugar donde lo han dejado los colegas que han abordado el tema anteriormente. De acuerdo a las descripciones hasta ahora vigentes, los métodos usados por los hispanocriollos para el cultivo de la vid eran notablemente rudimentarios. Así se desprende de los textos de Luque, Marianetti y Reina Rutini. El primero de ellos aseguró que el método tradicional "no constituye una forma racional ni próspera" 9 . Marianetti fijó una posición parecida:

9 Jorge Alfredo Luque, Manual vitícola, El cultivo de la vid, Mendoza, Riagro, 1957, 113. 
"Los viejos viñedos de Mendoza y San Juan presentaban la característica de variedades entremezcladas y los cultivos eran rudimentarios. Generalmente se trataba de plantaciones 'de cabeza' es decir, en las que las cepas -a diferencia de lo que ocurre en la actualidad- no estaban sostenidas ni por rodrigones ni por alambres. Prácticamente quedaban libres. Tenían aproximadamente una altura de un metro o más, y se podaban en forma que los racimos aparecieran en la parte superior de la cepa. Desde el punto de vista de la madurez de los mismos, no hay duda de que el sistema era bueno. Pero no lo era en cuanto a la producción. El cultivo 'de cabeza' era y ha seguido siendo el típico de regiones vitivinícolas no muy adelantadas de España e Italia. En cambio, en los países en que se ha prestado especial atención al problema, las plantaciones se han hecho en forma de parral o por hiladas o hileras, de unos cien metros de largo, con alambres (dos o tres) destinados a sostener los cargadores de las cepas y rodrigones de madera consistente, cada siete u ocho metros para sostén de los alambres y cepajes con 'cabeceros' o 'postes' más recios al final de las hileras" 10 .

La descripción de Marianetti es interesante. Entre otros elementos, nótese que el autor afirma taxativamente que "las plantaciones de cabeza no estaban sostenidas por rodrigones". Los conceptos del autor fueron aceptados por la comunidad académica y se estandarizaron en la literatura especializada. En su conferencia para ingresar como miembro de número de la Junta de Estudios Históricos de Mendoza, Reina Rutini señaló lo siguiente: “¿Cómo eran esos viñedos y las bodegas donde se elaboraba el vino en la época colonial y podríamos decir hasta mediados del siglo XIX? Las vides se plantaban en tierras con nivelaciones incipientes siguiéndose el sistema de arbolito o de cabeza, sin alambres ni postes"11. Al igual que Marianetti, Reina Rutini afirma que las viñas de cabeza no estaban sostenidas. Este punto de vista fue reproducido por uno de los más destacados historiadores económicos de Mendoza colonial, el cual reprodujo textualmente el párrafo anterior ${ }^{12}$. Más tarde, se publicó otro libro en el cual se volvió a reproducir el texto señalado ${ }^{13}$.

Algunas viñas cuyanas del siglo XIX parecerían confirmar esa tesis del descuido. Don Francisco Coria (1830) tenía "726 cepas de uva de cabeza muy mal plantadas y viejas"14. El inventario de bienes del presbítero José Godoy (1838) presentaba un panorama muy parecido: "En este terreno hay 3.009 cepas de uva muy viejas, sin rodrigones, desordenadamente puestas"15. Décadas más tarde, la viña de Juan Videla y Petrona Moyano presentaba una situación similar: “en el citado terreno hay 2.387 cepas de cabeza, uva negra, viejas y la mayor parte ladeadas o caídas y sin rodrigones, puestas en orden en hileras, pero con muchas

10 Benito Marianetti, El racimo y su aventura, la cuestión vitivinícola, Buenos Aires, Platina, $1965,89-90$.

11 Rodolfo Reina Rutini, "Conferencia en ocasión de ser incorporado como miembro de la Junta de Estudios Históricos de Mendoza”, Mendoza, 1985, 18.

12 Coria, op . cit., 117.

13 Rodolfo Reina Rutini, Los vitivinicultores mendocinos y su magia creadora de raíces, Mendoza, Bodega La Rural, Museo del Vino, 1994, 18.

14 Inventario de bienes de Francisco Coria, Mendoza, 20 de octubre de 1830. AHM, Carpeta 9, Documento 5, Folio 8 .

15 Inventario y tasación de bienes del presbítero José Godoy, Mendoza, 1 de marzo de 1838. AHM, Carpeta 23, Documento 3, Folio 49. 
fallas"16. También predominaban las notas de descuido en la viña de José Vicente Zapata (1851): "pasamos enseguida al sud de este terreno y se nos presentó el plantío de viña en el que contamos 1.418 cepas malas, en muy mal arreglo, mal cuidadas, a dos reales cada una, y 240 fallas a un real" 17 . Más adelante se identificó un parral en condiciones similares: tenía "252 cepas de uva moscatel, frutales, embraceradas, en mala condición su encatrado y ruinoso por el mal terreno, a dos reales"18.

Los documentos antes citados inclinan a pensar que la descripción de Marianetti fue muy rigurosa: viñas de cabeza, sin rodrigones, con "muy mal arreglo", "mal cuidadas" y "desordenadamente puestas". Pareciera que Marianetti hubiera estado presente en el segundo tercio del siglo XIX para observar directamente esas viñas y describirlas con precisión en sus libros.

Sin embargo, juntamente con los elementos negativos de esas viñas, también había otras dimensiones. Por ejemplo, la viña de Juan Videla y Petrona Moyano, a pesar de sus falencias, tenía un elemento distinto del criterio que el ensayista consideraba general: las cepas estaban "puestas en orden en hileras". También se cultivaban allí cepas de moscatel embracerado, lo cual refleja el manejo de sistemas de conducción. Estas fisuras hacen sospechar sobre la validez de la descripción de Marianetti como regla general de la forma de cultivar la viña en la etapa tradicional, es decir, antes de la llegada masiva de los inmigrantes europeos a tierras cuyanas.

Nos formulamos entonces la siguiente pregunta sobre la vitivinicultura tradicional: ¿en qué medida era válida la descripción de Marianetti, predominantemente negativa, de la forma de cultivar la viña, con variedades mezcladas, sin rodrigones, sin sistemas de conducción, con las cepas desordenadas dentro de la viña y, tal como dice el mismo autor, "sin criterios racionales"?

El tema requiere de un doble análisis. Por un lado, los datos tienen que ser confrontados con los manuales de agricultura de la época, para ver en qué medida las prácticas que ellos atribuyeron a los viticultores tradicionales cuyanos eran parte de un proceso mayor. Por otra parte, esas descripciones tienen que ser confrontadas con los referentes empíricos para, precisamente, constatar si eso ocurrió en Cuyo.

\section{MEDIOS DE SOSTÉN: LOS RODRIGONES}

La vid es una de las plantas más vivaces del reino vegetal y figura entre las que pueden lograr mayor expansión y duración. Paradójicamente, la parra es un arbusto trepador y, si no se apoya en medios de sostén, la cepa tiende naturalmente a reptar sobre el piso. La cepa de gran desarrollo y sin medios de sostén funciona únicamente sobre rocas o piedras peladas, sin tierra ni vegetación de contacto. En esos

16 Inventario y tasación de bienes de Juan Videla y Petrona Moyano. Mendoza, iniciado en Mendoza, 22 de noviembre de 1852. AHM, Carpeta 62, Documento 4, Testamentaria de Juan Videla y Petrona Moyano, $2^{\text {a }}$ pieza, iniciada junio 1866, folio 26.

17 Inventario de bienes de José Vicente Zapata, 30 de junio de 1851. AHM, Carpeta 64, Documento 6 , folio 44 .

18 Ibid., folio 48 v. El encatrado era una especie de catre de madera, sostenido por horcones, en el cual se conducían las parras. 
casos, la cepa rastrera puede desarrollar un paisaje cultural de singular belleza, pero solo existe en casos excepcionales. En general, el desarrollo de las viñas tal como se conocen ha requerido de estacas, tutores o rodrigones.

Como se ha dicho, varios autores han señalado que no se usaban rodrigones en la viticultura artesanal cuyana (Marianetti, Reina Rutini y Coria). De acuerdo a esa interpretación, la incorporación de esos rodrigones sería ajena a la tradición española y se habría introducido recién a partir del proceso de afrancesamiento y modernización de la industria vitivinícola cuyana. Sin embargo, en los últimos años ese enfoque se comenzó a revertir, sobre todo con los estudios de Rivera Medina. Esta investigadora ha detectado la presencia de los rodrigones desde la Edad Media en Europa, particularmente en las ordenanzas municipales de distintas ciudades, y, para el caso de San Juan, en documentos de comienzos del siglo XVII. Conviene ahora profundizar su análisis.

El empleo de rodrigones en las viñas es parte de una antigua tradición en la viticultura española. En algunas regiones de España, donde la madera para estos era escasa, se impusieron multas severas para castigar a los ladrones que, específicamente, robaran esos rodrigones. Así se establecía, por ejemplo, en el Fuero de Úbeda (1251-1285), cuyo título XI, dedicado a "las viñas y de la guarda de ellas", en su ley VI, establecía una multa de cinco maravedís por robar rodrigones ${ }^{19}$. Posteriormente, la legislación encargó esta tarea al costijero (funcionario designado por el ayuntamiento para la seguridad de las viñas). Mediante una ordenanza dada en Valladolid en 1507, se invistió al costijero de las atribuciones necesarias para detener al ladrón de rodrigones ${ }^{20}$.

Junto con encargarse de la seguridad de los tutores, las ordenanzas municipales se ocuparon también de reglamentar los cuidados que debían tenerse con los rodrigones de las cepas, para prolongar su vida útil, a la vez que recomendaban las maderas más adecuadas para rodrigones, particularmente las ramas de sauce. Ello se reflejaba, por ejemplo, en las ordenanzas municipales de Orduña en 149921. Por su parte, las de Bilbao también enfatizaban la importancia de cuidar los rodrigo$n^{22}$. La recurrente presencia de los tutores en las ordenanzas municipales españolas muestra la importancia que se les atribuía en la vida económica y social.

El rodrigón también se hizo visible en el primer manual español de agricultura: "en acabando de poner la vid, ha luego menester un ayo como los niños para que la defienda y encamine"23. Y ese rodrigón debía tener una serie de características: tenía que ser de buenas maderas (preferentemente castaño), recto, seco y firme; también se estipulaba la profundidad a la cual debía ser enterrado y sus medidas recomendadas:

19 Fernando Suárez Bilbao, El fuero judiego en la España cristiana. Las fuentes jurídicas siglos V al XV, Madrid, Dykinson, 2000, 200.

20 Ana María Rivera Medina, "Producción local, abastecimiento urbano y regulación municipal: El marco legal del vino en Bilbao (siglos XIV-XVI)", en Espacio, tiempo y forma 19, Madrid, 2007.

21 Javier Enríquez Fernández et al., Colección documental del Archivo Municipal de Orduña (1271-1510), San Sebastián, Eusko Ikaskuntza, colección Fuentes Medievales del País Vasco No 52 , 1994, Tomo I, Documento 29, Orduña, 6 de noviembre de 1499.

22 Enríquez Fernández, op . cit., I:25, 65, 66, 74, 79, 97, 98, 228.

23 Herrera, op . cit., 272. 
“Todo rodrigón sea seco, derecho, porque la vid guiándose por él, se arme derecha. Tenga algunos gajos para que la vid se asga a ellos con sus tijeretas. Entre hondo so tierra, porque esté firme y no se menee, que hace mucho daño al sarmiento, y vaya bien agudo por bajo, porque cuele bien; no sea muy largo, porque no coja viento, hasta que tenga cuatro palmos sobre tierra; sea del gordor de una asta de lanza y no menos" 24 .

También se llegó a especificar la posición que este debía tener con respecto a la cepa, según las temperaturas y el viento, para ser más efectivo. Trescientos años después, otro manual español insistía sobre el tema: "Desde la primera poda se arrimará un tutor a cada planta, para que sosteniendo el débil sarmiento, siga derecho y salga del criadero bien formado, y no torcido, como sucedería si se le dejase arrastrar por el suelo" 25 . Evidentemente, la viticultura española tuvo siempre conciencia de la importancia del tutor en el cultivo de la vid. Y estos conocimientos se derramaron en la viticultura americana.

El caso cuyano revela aspectos de interés. El uso de rodrigones tuvo amplia difusión en la viticultura cuyana. Las fuentes registraron 35.000 plantas con tutores, la mayor parte en la época colonial (9 viñas con 23.333 rodrigones), mientras que en el período independiente se hallaron cifras menores (7 viñas con 11.083 rodrigones).

\section{CUADRO III}

FORMAS ARTESANALES DE CULTIVAR LA VID. CUYO, SIGLOS XVII-XIX

\begin{tabular}{|c|c|c|c|c|c|}
\hline & \multicolumn{2}{|c|}{ Colonial (antes de 1810) } & \multicolumn{2}{|c|}{ Independiente (1810-1870) } & \multirow{2}{*}{$\begin{array}{r}\text { Total } \\
78.504\end{array}$} \\
\hline Hileras & 68.038 & $87 \%$ & 10.466 & $13 \%$ & \\
\hline Rodrigones & 23.333 & $68 \%$ & 11.083 & $32 \%$ & 34.416 \\
\hline Viña con cepa de poda & 12.965 & $100 \%$ & 0 & $0 \%$ & 12.965 \\
\hline Viña con cepa de cabeza & 0 & $0 \%$ & 132.946 & $100 \%$ & 132.946 \\
\hline Viña con cepa de bracero & 1.347 & $3 \%$ & 40.300 & $96 \%$ & 41.647 \\
\hline Parral & 184 & $3 \%$ & 6.147 & $97 \%$ & 6.331 \\
\hline
\end{tabular}

Fuente: Elaboración propia a partir de Archivo Histórico de Mendoza, Archivo General de la Provincia de San Juan y Archivo del Poder Judicial de San Juan.

La madera usada para los tutores era otro elemento importante. Lo usual era el algarrobo (Ceratonia siliqua), material usado en las viñas de los jesuitas, de Juan Jordán y de María Dominga Quevedo, entre otras ${ }^{26}$, pero también se utilizaron alternativas: don Juan Jordán empleaba rodrigones de un arbusto de los Andes

\footnotetext{
24 Idem.

25 Sandalio Arias, op. cit., 320.
}

26 Inventario de bienes de Juan Jordán. Mendoza, 5 de septiembre de 1826. AHM, Carpeta 29, Documento 1, folio 12 v. Inventario y tasación de bienes de María Dominga Quevedo. Mendoza, 12 de junio de 1835. AHM, Carpeta 46, Documento 3, folio 15. 
llamado altepe (Proustia ilicifolia) ${ }^{27}$ y la viña de Juan Videla y Petrona Moyano usaba rodrigones de guindo (Prunus cerasus) ${ }^{28}$.

El valor de la viña guardaba relación con la calidad del trabajo cultural y los rodrigones influían en ello. De acuerdo a un registro de 1748, los rodrigones se podían conseguir en el mercado a un valor de 2 pesos por 100 unidades. El valor de la viña dependía, al menos en parte, de los tutores. Al tasarse un viñedo, el precio de mercado se consideraba para la cepa con rodrigón. En caso de no tener este apoyo, los tasadores rebajaban el valor de la viña y hacían explícita la causa. Así, por ejemplo, al valuar una de las viñas de don José Clemente Benegas, los tasadores señalaron que "en el cuartel del Naciente de la misma viña hay 1.710 cepas de uva sin rodrigones en la mayor parte de ellas y de mala calidad, las que [se tasan] a $1 \frac{1}{2}$ real... 320,5 pesos" 29 . Años más tarde, al valuarse una viña del padre Eduardo Larreta, se usó el mismo criterio: "En dicho sitio se contaron 982 cepas de uva negra en cabeza, que aunque son nuevas pero están sin rodrigones y algo estropeadas, por lo que se tasan a 1 real cada una; [en total suman] 123 pesos" 30 .

Si se compara la calidad del uso de los rodrigones en los dos períodos examinados (antes y después de la Independencia), se detecta una ventaja del primero. Los registros de viñas con mención de rodrigones de la época colonial, siempre tenían un carácter positivo, en cambio, en el período independiente, la situación era bastante irregular. Algunas viñas de esta etapa estaban "bien arrodrigonadas", como la de Nazar Gómez ${ }^{31}$, pero también había chacras descuidadas. Margarita Medina, por ejemplo, tenía "308 cepas desarregladas y sin rodrigones [tasadas] a real cada una" 32 .

La viña del padre Juan Godoy tenía cepas "viejas, sin rodrigones y desordenadamente puestas" 33 y una de las viñas de Juan Videla y Petrona Moyano tenía “2.387 cepas de cabeza, uva negra, viejas y la mayor parte ladeadas o caídas y sin rodrigones, puestas en orden de hileras, pero con muchas fallas" 34 .

Efectivamente, algunas viñas cuyanas presentaban un aspecto descuidado. Sin embargo, fueron casos aislados, que no representaban la corriente principal del sistema vitivinícola regional. Conviene, por tanto, examinar el conjunto de las viñas, para identificar los modos en que los cuyanos desarrollaron para cultivar sus cepas.

27 Junto con 530 cepas con rodrigón de algarrobo, don Juan tenía otras 250 con rodrigón de atepe; aquellas se valuaron a $3 \frac{1}{2}$ reales y estas un poco menos, a 3 reales. Inventario de bienes de Juan Jordán, op . cit., folio $12 \mathrm{v}$.

28 Inventario y tasación de bienes de Juan Videla y Petrona Moyano. Mendoza, 17 de agosto de 1866. AHM, Carpeta 62, Documento 4, folio 26.

29 Testamentaria de José Clemente Benegas, 3 de febrero de 1835 . AHM, Carpeta No 6 , documento $\mathrm{N}^{\mathrm{o}} 18$, Folio 34.

30 Tasación de bienes de Eduardo Larreta, Mendoza, 11 de noviembre de 1851. AHM, Carpeta $\mathrm{N}^{\circ} 31$, Legajo $\mathrm{N}^{\circ}$ 2, Folio 11.

31 Inventario de bienes de Nazar Gómez. Mendoza, 20 de febrero de 1834. AHM, Carpeta 22, Documento 8 , folio 7 .

32 Inventario de bienes de Margarita Medina. Mendoza, 20 de agosto de 1813. AHM, Carpeta 41, Documento 7, folio $9 \mathrm{v}$.

33 Inventario y tasación de bienes del presbítero José Godoy. Mendoza, 24 de febrero de 1838. AHM, Carpeta 23, Documento 3, folio $49 \mathrm{v}$.

34 Inventario y tasación de bienes de Juan Videla y Petrona Moyano. Mendoza, 17 de agosto de 1866. AHM, Carpeta 62, Documento 4, folio 26. 


\section{CEPA DE VASO O “DE CABEZA"}

Lo que en España se denomina "cepa de vaso", en las fuentes americanas del siglo XIX se llamaba "cepa de cabeza" y era la forma de cultivo más difundida en la viticultura artesanal cuyana de la época. La afirmación de Marianetti ha resultado consistente con los referentes empíricos compulsados. De todos modos, "cepa de cabeza" es un concepto complicado, debido a las dificultades de definición. Al confrontar el término con los manuales agrícolas españoles, surge la primera novedad: no se usaba la expresión "cepa de cabeza" en esos textos. Sin embargo, se pueden rastrear algunos conceptos cercanos.

En el texto fundacional de la agricultura española, se hicieron las primeras menciones a la "cabeza" de la cepa. Allí se estipula que el labrador "hará hoyos, pondrá sarmientos en otro, tumbará vides de cabeza, echará mugrones"35. En el Diccionario de Autoridades se citó justamente este párrafo, para explicar el significado de "mugrón" 36 . Así, el término "cabeza" quedó asociado a la reproducción por medio de mugrones. En efecto, se decía "echar de cabeza las vides y otras plantas cuando, sin cortarlas de su cepa, las vuelven a enterrar para que hagan barbas en la tierra y después las cortan cuando ya están presas"37.

Además su importancia en la reproducción, también se usó el término "cabeza" para referirse a la maduración de la planta. La cabeza era la parte principal de la cepa, y el labrador debía prestar especial atención a su desarrollo.

"Hecha la plantación de la viña se asistirá con repetidas labores y con la poda discreta
que conduce a formar su tronco y cabeza, hasta que, habiéndose vigorizado, empiece a
brotar sarmientos fuertes y el tronco o pie vaya adquiriendo aquel grueso que le corres-
ponde. Al tercero o cuarto año ya se podrá haber criado la cepa, formando su cabeza y
repartido esta en tres o cuatro puestos o pulgares, que en lo sucesivo serán las ramas
madres de la vid" 38 .

El sistema de cabeza, dentro de la vitivinicultura argentina, tuvo su período de apogeo en el siglo XIX, hasta que, a finales de esa centuria, comenzó a ser desplazado por las viñas con espalderas y sus alambrados. En la primera mitad del siglo $\mathrm{XX}$, el desplazamiento llegó ser casi total y al promediar esa centuria, muy pocas viñas se mantenían todavía con el tradicional método "de cabeza". De todos modos, los viticultores que se interesaron en estudiar las viñas y escribir sus reflexiones y recomendaciones en esa época detectaron que todavía existían esas cepas. Así se refleja en los estudios de Luque (1957) y Vega (1962). El primero describió el tema en los siguientes términos:

"En Argentina, las viñas se cultivan en sistemas de espalderas o contra espalderas y parrales; no obstante, ha sido posible notar también algunos pequeños paños con viña

35 Herrera, op. cit., 440.

36 Real Academia Española, Diccionario de Autoridades (1726-1739), Madrid, Gredos, 1964, II, 217.

37 Sebastián Covarrubias, Tesoro de la Lengua castellana o española [1611], Madrid, Editorial Castalia, 1995, 223.

38 Sandalio Arias, op. cit., 323. 
'de cabeza' a pesar de que para las variedades explotadas en la zona vitivinícola, no constituye esta última una forma racional ni próspera" 39.

El autor usaba adjetivos negativos para calificar la calidad de las viñas "de cabeza", enfoque que era un reflejo de las tendencias de los viticultores de ese tiempo, donde predominaba una corriente contraria a ese tipo de cultivo, ya que no se lo consideraba recomendable. De todos modos, el texto de Luque, que era abundante en adjetivos y pobre en información, no logró definir con claridad en qué consistía específicamente la cepa de cabeza. En ese sentido, mayor precisión logró el texto de Vega:

\begin{abstract}
"Dentro de los sistemas de pequeña expansión vegetativa, se considera el sistema 'en vaso' o 'gobelet'. También es conocido en nuestro medio como 'cabeza'. Constituye el sistema de conducción de la vid más difundido en el mundo dado lo reducido de su costo de unificación y su adaptación a condiciones ecológicas extremas. No es recomendable para uvas de mesa. Los primeros viñedos argentinos se instalaron conforme a este sistema y todavía se lo encuentra en las provincias de La Rioja, Catamarca y Santiago del Estero, y aún por cuando con una formación muy defectuosa. Este sistema presentaría ponderables ventajas de orden económico, entra las que cabe mencionar la eliminación de los postes rodrigones y alambres de la contraespaldera común. Deberá colocarse a cada planta un tutor de por lo menos, 1,50 metros de alto; pero a mayores espaciamientos (3,00 por 2,00 metros; 3,00 por 3,00 metros, etc.) podría utilizarse tutores más cortos y de menor calidad, con el fin de acompañar la planta solo en los primeros 4 o 5 años. Como la poda empleada es a pitones de dos y tres yemas, se prescinde de atadura y por ser más sencilla, no requiere mayor especialización en el podador" 40 .
\end{abstract}

La descripción de la cepa de cabeza entregada por Vega resulta suficientemente clara: esta podía usar rodrigones permanentes o no; aunque también era posible que solo se apoyara en un tutor sencillo, apenas para acompañar el crecimiento de la planta en sus primeros años. Por otra parte, el autor sitúa la cepa de cabeza como un modo de cultivo que tiende a generar pequeña expansión vegetativa, ya que este tipo de parra no tendría largos sarmientos. Asimismo, enfatiza la amplia difusión de este método y su profundidad histórica y aclara, además, que es el que requiere menor intensidad de trabajo cultural, porque no requiere atadura y es más fácil de podar.

En la viticultura artesanal cuyana también se usaron conceptos análogos. Concretamente, se hablaba de "viña de poda" o "viña de cabeza". El uso de estas dos expresiones fue variable en el tiempo: en el período colonial, las fuentes mencionan la "cepa de poda", mientras que, después de la Revolución, se empleó el concepto "cepa de cabeza".

Los registros documentales revelan la recurrencia en el uso de esas expresiones. Así, por ejemplo, en 1779 don Diego Pringles tenía 1.990 cepas de poda en Men-

39 Luque, op. cit., 113.

40 José Vega, Alberto Alcalde, Wigberto Cinta, Moisés Nazrala y Luis Laborde, "Experiencias con sistemas de conducción y poda de la vid", IDIA 179, Buenos Aires, noviembre de 1962, 5. 
doza $^{41}$ y ese mismo año, pero en San Juan, la hacienda de Pedro Sarmiento exhibía “una viña llamada 'la vieja' con 3.000 plantas frutales y las más de poda" ${ }^{2}$. Esta tradición se consolidó en el tiempo: hacia 1795 don Ignacio Moyano poseía una viña con 7.975 cepas de este tipo ${ }^{43}$. Conviene señalar que estas plantas estaban bien valoradas. Las de Pringles se cotizaron a $3 \frac{1}{2}$ reales la cepa, mientras que las de Moyano se tasaron en $3 \frac{1}{4}$ reales cada una. Era un precio ligeramente inferior al de las cepas embraceradas.

Después de la Independencia se dejó de emplear esta expresión y en su lugar empezó a usarse "cepa de cabeza". Este hecho se produjo en forma simultánea con España (la importancia de la cabeza de la parra se menciona en el texto de Sandalio Arias, escrito a mediados del siglo XIX). Actualmente, todavía pueden verse viñas con cepas de cabeza en las zonas más tradicionales de Chile, como por ejemplo, en el secano costero de la Región del Maule. Este mismo sistema, tal como sostenían los autores citados, tenía amplia difusión en Mendoza antes de la llegada de los inmigrantes, aseveración se pudo confirmar en la investigación de archivo.

El relevamiento de información en terreno, a partir de antiguos viticultores, demuestra que en Cuyo se usaron dos formas de cultivo de cabeza: con y sin rodrigón. La cepa de cabeza sin este tutor era la más pequeña de todas y se podaba a "pitón", concepto que se usaba a comienzos del siglo XVIII para denominar, en una de sus acepciones, al "renuevo del árbol cuanto empieza a abotonar"44. La cepa de cabeza se podaba a pitón para reducir su crecimiento al mínimo. Este método se usaba en los suelos pobres, en los cuales no era conveniente un mayor desarrollo de la planta, pues su crecimiento estaba limitado por los nutrientes, ya que la única forma de obtener frutos adecuados era con una fuerte restricción al tamaño de la planta. La cepa de cabeza podada por este método era muy baja, no superando los 40 centímetros de altura sobre el nivel del suelo.

La cepa de cabeza con rodrigón, en cambio, alcanzaba mayor altura, llegando a tener entre 60 y 80 centímetros de altitud, por lo que se aplicaba en suelos de mejor calidad que la anterior. Como medio de sostén se usaba una estaca, tutor o rodrigón. Al igual que la cepa de cabeza "a pitón", la cultivada con rodrigón no tenía medios de conducción y solo se diferenciaba de la anterior por su mayor altura, lo cual significaba una ventaja, al mantener a los racimos separados del suelo, evitando muchos problemas.

El análisis de las propiedades de los viticultores registrados en el censo de 1825 permitió detectar datos precisos sobre la forma de cultivar la viña en 56 unidades productivas, con 172.352 parras. Sobre ese total, las cepas de cabeza eran 127.622,

41 Inventario de bienes de Diego Pringles. Mendoza, 12 de julio de 1779. AHM, Carpeta 263, Documento 22, folio $6 \mathrm{v}$.

42 Inventario de bienes de Pedro Sarmiento. San Juan, 10 de setiembre de 1779. Archivo del Poder Judicial de San Juan (en adelante APJSJ), Libro José Sebastián de Castro, Protocolo 1779, folio 160 .

43 Tasación y partición extrajudicial de bienes de Ignacio Moyano. Mendoza, 25 de mayo de 1794. AHM, Carpeta 259, Documento 1, folio $2 \mathrm{v}$.

44 Real Academia Española, Diccionario de Autoridades, op. cit., III, 285. 
lo cual representaba el $74 \%$. En otras palabras, tres de cada cuatro parras cultivadas en Mendoza eran cepas de cabeza. Esta era, sin duda, la modalidad de cultivo más difundida en la provincia. Empero, no todos los viticultores adherían a este método. De un total de 59 empresarios dedicados a la viticultura, el sistema de "cepa de cabeza" era empleado por $35(62,5 \%)$. Por lo tanto, más de un tercio de los viñateros de Mendoza prefería cultivar las cepas con otros métodos.

Esta modalidad de cultivo no fue registrada en Mendoza ni en San Juan durante la época colonial. El registro más antiguo hallado corresponde a la década de 1820 . En 1822 se registraron 4.265 cepas de cabeza de don José Díaz Barroso; en 1826, 4 de Juan Antonio Chavarrieta y 1.500 de Juan Jordán; en 1827, 4.603 de Carmen Correa; y en 1828, otras 6.000 a nombre de Carmen Almandos. En esa década de produjo la difusión de la cepa de cabeza, modalidad que superó a todas las demás y se estandarizó como cultivo hegemónico en las décadas de 1830, 1840 y 1850.

Desde el punto de vista de las variedades, la cepa de cabeza estuvo muy cerca de la uva negra. En las viñas de cabeza en las cuales se registró el tipo de uva, había 10.760 plantas de uva negra (98\%), 214 de moscatel (2\%) y 3 de uva mollar. Por lo tanto, casi la totalidad de las viñas cultivadas con este método estaba constituida por la uva negra, llamada también "uva país" en Chile, "negra corriente" en Perú y "criolla chica" actualmente en Argentina.

Con respecto a los precios, la cepa de cabeza de mala construcción se valuaba en 1 real la planta, desde donde podía subir a $1 \frac{1}{2}, 2$ y $2^{1 / \frac{2}{2}}$ reales, mientras la de buena construcción se apreciaba en 3 reales, aunque excepcionalmente se podía valuar en 4 . De todas las formas de cultivo de la uva, las viñas de cepa de cabeza eran las menos valiosas (se tasaban a un precio inferior al de las cepas de bracero o de parral encatrado).

Las viñas de cabeza, tan difundidas en el siglo XIX, comenzaron a declinar hacia el final de esa centuria. La transformación comenzó en Mendoza y fue más lenta en San Juan. Al comenzar el nuevo siglo, Mendoza cultivaba 21 mil hectáreas de viñas, 18 mil con el sistema Guyot y 3 mil de cabeza. Así, mientras en esa ciudad este método representaba poco menos del $15 \%$ del total de los viñedos, en San Juan superaba el 50\% (5 mil hectáreas de sistema Guyot y 6 mil de cabeza $)^{45}$. En los años posteriores, la viticultura argentina profundizó la tendencia a abandonar la cepa de cabeza y extender el sistema Guyot. En el I Censo Nacional de Viñedos (1936), se detectó que solo se usaba este método para cultivar 3.958 hectáreas de viñas, lo cual representaba el 2,7\% del total de los viñedos $\operatorname{argentinos}{ }^{46}$. En los años posteriores, mientras la viticultura siguió creciendo, las viñas de cabeza continuaron su disminución. En el Censo de Viñedos de 1965 se registraron solamente 2.873 hectáreas de viña con este sistema, el

45 Arminio N. Galanti, La industria viti-vinícola argentina. Su estado actual y medios de mejorarla y fomentarla. Estudio crítico ilustrado, Buenos Aires, Talleres S. Ostwald y Compañía, 1900, 61 y $124-125$.

46 Junta Reguladora de Vinos, Censo de viñedos, Año 1936. Actualizado de acuerdo a las extirpaciones realizadas en los años 1936 a 1938 en cumplimiento de las leyes 12.137 y 12.355 , Buenos Aires, 1938. 
$1,04 \%$ del total nacional ${ }^{47}$, mientras que años más tarde, el V Censo Vitícola (1991) identificó apenas 354 hectáreas de viña de cabeza, apenas el 0,16\% de la viticultura argentina ${ }^{48}$.

\section{SISTEMAS DE CONDUCCIÓN: CEPAS DE BRACERO O "EMBRACERADAS"}

En la vitivinicultura moderna, la disponibilidad de alambre constituye una facilidad decisiva para la conducción de la vid. El alambre es un medio relativamente barato y fácil de manejar. Pero en la etapa anterior, la ausencia de este recurso planteó un desafío mayor para los viticultores. ¿Cómo conducir los sarmientos de las parras para que pudieran extenderse y absorber el sol de la mejor manera posible, sin alambres?

La viticultura colonial de América Latina procuró resolver este problema con cuatro caminos distintos: viñas en barbacoa; cepas en sogas; viñas embraceradas y parrales encatrados. Los sistemas de barbacoa se usaron en Perú y en el noroeste argentino, sobre todo en Catamarca, en cambio en Cuyo solo se utilizaron las viñas embraceradas y los parrales encatrados.

El sistema de conducción de barbacoa se puso en marcha en la época colonial y mantuvo cierta vigencia hasta mediados del siglo XX, sobre todo en Perú. En esa época, este país cultivaba 7.500 hectáreas de viña y elaboraba 15 millones de litros de vino, en sus tres regiones vitivinícolas: el valle de Chincha, el valle de Surco y el Valle de Ica. En este último, que era el más moderno, predominaba la viña en espalderas con alambre; pero en el valle de Chincha, donde se cultivaban 2 mil hectáreas, predominaban las viñas en barbacoa. Este sistema combina el empleo de pilares de barro, sostenes de madera y apoyos de cañas y cordones:

"La vid se planta en dos por dos metros de distancia y como sostén utilizase la madera complementada con cañas. Los travesaños de madera (denominados madre o maestra) se apoyan sobre pilares de barro compactado de 1,50 metros de altura. Las plantas se extienden en uno, dos o tres cordones hasta cubrir el espacio asignado a cada cepa y terminan en pitones de dos o tres gemas. La poda se efectuaría generalmente en el mes de agosto. Como puede deducirse las plantas tienen madera vieja en demasía, con poda pobre, que limitan las posibilidades productivas" 49 .

Los viticultores cuyanos no desarrollaron el cultivo en "barbacoa", sino el embracerado. Al igual que el anterior, este sistema procuraba conducir los sarmientos para lograr un mejor despliegue de las hojas de parra para absorber el sol. No se empleaban pilares de barro ni cañas, sino horcones y varillas de sauce o mimbre, materiales que se usaron en las viñas cuyanas durante trescientos años, hasta la introducción del alambre.

47 Síntesis de estadística vitivinícola 1966, 20.

48 Instituto Nacional de Vitivinicultura, Estadística vitivinícola argentina. Año 1991, Primera parte, Actualización V Censo Vitícola, Mendoza, INV, 1992, 13.

49 José Vega, “Aspectos de la viticultura del Perú”, IDIA 157, Buenos Aires, enero de 1961, 3-4. 
La viña de bracero se difundió tanto en Europa como en América. Jules Guyot identificó esta modalidad en Francia y propuso su expansión; como resultado, algunos ingenieros agrónomos lo denominan actualmente "sistema Guyot". Se trata de una modalidad empleada también en España y que se conoce como "embrazar" la parra, la cual consiste en "disponer las vides en dos, tres o cuatro brazos con tal arte y orden que formen una cruz y todos salgan como nacidos del tronco, todo lo cual es obra de los diestros podadores" 50 . En Cuyo se usaba este sistema con tres modalidades: medio bracero, doble bracero y "a los cuatro vientos".

Los sistemas de conducción de la vid tuvieron una interesante evolución histórica en la región. El registro más antiguo en el reino de Chile corresponde a la ciudad de Santiago en el siglo XVII, donde el capitán Jerónimo de la Cámara Justiniano cultivó una viña con estas características, en el último tercio de ese $\operatorname{siglo}^{51}$. Después de su fallecimiento, al realizarse el inventario de sus bienes, se registraron casas, bodegas, lagares y viñedos, entre los cuales había “4.800 plantas de viña en que se incluyen 600 plantas de parral y braceros todo ello bien arrodrigonado" 52 . Desde la capital de Chile, este modo de conducción se difundió hacia otras partes del reino.

El cultivo por braceros atravesó la cordillera y llegó a Cuyo a comienzos del siglo XVIII. Posiblemente, esta innovación haya sido llevada por los arrieros, viajeros, comerciantes, familiares o amigos que atravesaban la cordillera para transportar cargas, visitar parientes o, sencillamente, asentarse allí y practicar sus oficios. Una vez introducida, esta forma de cultivar las cepas se difundió ampliamente entre los viticultores locales.

El bracero como sistema de conducción para las viñas cuyanas se usó por primera vez en la década de 1740. De acuerdo a la documentación compulsada, el primer antecedente corresponde a la viña de Ignacio y Clemente Godoy. Se trata del mismo grupo familiar que introdujo el uso de recipientes de madera para conservación y crianza de vinos, en reemplazo de las botijas y tinajas de cerámica. Al realizar la partición entre sus herederas (1744), se realizó un inventario de bienes, en el cual se detectó "una hilera de parral de varias uvas, parte en bracero, y parte sobre catre de madera"53. Casi simultáneamente, el inmigrante francés Miguel de Arizmendi cultivaba 425 cepas de moscatel y uva negra embraceradas. El mejoramiento en el cultivo de la vid fue acompañado, en este caso también, por la preocu-

50 Augusto Jurado, Las voces del vino y la vid, Madrid, C \& C, 2001, 116.

51 Se trata de un personaje interesante, pues no pertenecía a la élite chilena: debía sobre llevar el estigma de ser hijo natural, pues su padre era canónigo de la Catedral de Santiago. A pesar de su origen bastardo, logró acceder a la propiedad y a las técnicas de cultivar la vid y elaborar el vino, pues su padre cultivaba la viña de Cajamarca. Juan Guillermo Muñoz, "Viñas en la traza de Santiago del Nuevo Extremo y chacras colindantes (siglos XVI-XVIII)", en Revista de Historia Social y de las Mentalidades 10:1, Santiago, 2006, 125-126.

52 Archivo Nacional de Chile (en adelante AN), Escribanos de Santiago 396 foja 101. Marco Ganter Araya, "Viñas en Santiago a comienzos del siglo XVIII", Palimpsesto 6, Santiago, 2006 [www.palimpsestousach.cl]; y Viñas en testamentos y ventas, siglo XVII, Tesis de Licenciatura en Historia, Universidad de Santiago de Chile, Santiago, 2008, 58.

53 Inventario de bienes del difunto Ignacio Godoy, Mendoza, 27 de octubre de 1744. AHM, Carpeta 246, Documento 21, testamentaria de Ignacio Figueroa Godoy (iniciada: 12 de setiembre de 1725) folio $13 \mathrm{v}$. 
pación por mejorar la calidad de los vinos. Las innovaciones de Godoy y Arizmendi no tardaron en ser replicadas por otros viticultores cuyanos en la segunda mitad del siglo XVIII. En 1750 el inventario de bienes de don Joseph de Coria reveló la presencia de 210 cepas embraceradas de moscatel y uva negra; y ocho años después, Juan Crisóstomo Jiménez tenía dos parrales cultivados con este método, uno de moscatel y el otro de uva negra. Paralelamente, los jesuitas cultivaron 219 cepas embraceradas; Diego Pringles 315 e Ignacio Moyano 184 de moscatel ${ }^{54}$.

El bracero fue la mejor forma que encontraron los cuyanos para cultivar la viña. La parra se sostenía con rodrigón y llegaba a tener entre 60 y 80 centímetros de altura, desde donde se conducían los sarmientos. Las cepas de un sarmiento se llamaba "medio bracero" y las de dos eran conocidas como "doble bracero". En casos excepcionales se empleaba el sistema "a cuatro vientos", tal como se registró en las propiedades de Candelaria Vargas e Ignacio Ferramola ${ }^{55}$.

Los viticultores cuyanos conocían y aplicaban este método. Las viñas de bracero estaban presentes en el $83 \%$ de las propiedades vitivinícolas de Mendoza y el $90 \%$ de San Juan. Claro que, es necesario decirlo, dentro de sus viñas este método se usaba en pequeña proporción, pues solían priorizar otras formas de cultivo, sobre todo la cepa de cabeza. En total se registraron más de 40 mil cepas embraceradas, lo cual representaba casi la cuarta parte del total de los cultivos vitícolas de Mendoza. En San Juan se identificaron 2.941 plantas con este sistema de conducción, lo cual representaba el $22 \%$ del total.

Las viñas de bracero se sostenían con horcones, que eran palos gruesos, sólidos y resistentes, que se usaba también en la construcción, sobre todo para sostener el techo de las galerías.

Más del $80 \%$ de las viñas de bracero estaban sostenidas por horcones de algarrobo, que era la madera más usada en su fabricación. Por ejemplo, José Díaz Barroso (1822) cultivaba "3.000 cepas de moscatel embraceradas con horcones de algarrobo a $3 \frac{1}{2}$ reales: 1.312 pesos 4 reales; en la huerta: 241 cepas de moscatel embraceradas y con buena horconería de algarrobo a 4 reales: 120 pesos 4 reales"56. Pero también se usaron otras maderas para confeccionarlos, aunque con frecuencia, las fuentes no definían cuáles. María Lorenza Moyano (1848) cultivaba "458 plantas de moscatel frutales con horcones de varias maderas a 2 reales cada una: 114 pesos 4 reales. Item. 230 cepas de moscatel nuevas frutales con horcones de varias maderas a $1 \frac{1}{2}$ real cada una: 14 pesos 3 reales" 57 . En algunos casos se

54 Inventario de bienes de Joseph de Coria. Mendoza, 26 de junio de 1750. AHM, Carpeta 238, Documento 10, folio 9 v. Testamento de Juan Crisóstomo Jiménez. Mendoza, 13 de noviembre de 1758. AHM, Protocolo de Escribanos $\mathrm{n}^{\circ} 71$, folio 130 v. Inventario de bienes de Diego Pringles. Mendoza, 12 de julio de 1779. AHM, Carpeta 263, Documento 22, folios 6 y 7. Tasación y partición extrajudicial de bienes de Ignacio Moyano. Mendoza, 25 de mayo de 1794. AHM, Carpeta 259, Documento 1 , folio $2 \mathrm{v}$.

55 Inventario y tasación de bienes de María Candelaria Vargas. Mendoza, 8 de marzo de 1821. AHM, Carpeta 19, Documento 6, Folio 13.

56 Inventario de bienes de José Díaz Barroso, Mendoza, 30 de marzo de 1822. AHM, Carpeta 15, Documento 5, Folios 2, 21 y 21 v.

57 Inventario de bienes de María Lorenza Moyano, Mendoza, 30 de diciembre de 1848. AHM, Carpeta Documento Folios 33, 47 y 51. 
usaron horcones de retamo, guindo y peral. Así, por ejemplo, Vicente Pescara (1840) cultivaba "963 cepas de bracero con horcones de algarrobo y retamo la mayor parte de ellas de moscatel a $2^{1 /} / 2$ reales cada una: 300 pesos $7 \frac{1}{2}$ reales" 58 . Por su parte, Juan Videla (1866) cultivaba sus cepas sostenidas con "24 horcones de guindo y peral que sostienen el embracerado" 59 . En resumidas cuentas, cuatro de cada cinco horcones de las viñas de Mendoza eran de algarrobo. El caso restante podía variar entre distintas opciones, como retamo y frutales.

La "varazón" era el conjunto de varillas que se usaban para cumplir la función que, desde fines del siglo XIX, asumiría alambre. En las viñas embraceradas de Cuyo, la "varazón" era habitualmente de sauce (salix) o álamo (populus), los cuales eran igual de frecuentes, con una leve supremacía del sauce. En casos excepcionales se podían emplear otros materiales, como las cañas.

El sauce era muy apreciado por los viticultores, pues resultaba abundante y flexible. María Dominga Quevedo (1835) cultivaba "1.772 cepas de uva negra, con sus respectivos rodrigones de algarrobo, embraceradas con madera de sauce, frutales y en buen estado, que se tasó a 2 reales cada una, importan 443 pesos"60. Le seguía en importancia el varazón de álamo, que representaba casi la otra mitad del total de las viñas embraceradas. En San Juan, la viña de Lugares Riveros (1864) tenía "382 parras de moscatel con horcones de algarrobo, con varilla de álamo en mediana condición, a 50 centavos"61, y la de Eusebio Ríos "14 parras de uva mollar que ocupan 22 horcones de algarrobo, medianamente embraceradas con varillas de álamo, con todo su contenido de horconado tase a 9 reales parra impor$\tan 15$ pesos 6 reales" 62 .

En Mendoza, Juan Jordán (1826) tenía “184 cepas de moscatel embraceradas que forman 8 hileras con horcones de algarrobos y bracero de varas de álamo a 4 reales: 92 pesos" ${ }^{63}$; María Lorenza Moyano (1848), "458 plantas de moscatel frutales con horcones de varias maderas y embracerado de madera de álamo a 2 reales cada una: 114 pesos 4 reales"64; y Juan Videla (1866), nueve parras de moscatel, cuyo "embracerado se compone de 26 varillas de álamo"65. En algunos casos se usaba el sistema mixto: parte sauce y parte álamo. Por ejemplo, Melchor Molina (1831) tenía

58 Inventario de bienes de Vicente Pescara, Mendoza, 4 de noviembre de 1840. AHM, Carpeta 41 Documento 7 Pieza 2 Folio 65.

59 Inventario y tasación de bienes de Juan Videla. Mendoza, 17 de agosto de 1866. AHM, Carpeta 62, Documento 4, Folios 34 v y 43.

60 Inventario de bienes de María Dominga Quevedo, Mendoza, 12 de junio de 1835. AHM, Carpeta 46, Documento 3, Folio 15, 16 y 31.

61 Cesión de bienes de don Lugares Riveros, San Juan, 6 de octubre de 1864. APJSJ, Caja 31, Estante 2, Expediente 254, Folio 43 v.

62 Cesión de bienes de Eusebio Ríos. San Juan, 21 de abril de 1865. APJSJ, Carpeta 28, Estante 2, Expediente 236, Folio $14 \mathrm{v}$.

63 Inventario de bienes de Juan Jordán, Mendoza, op. cit., Folio 2.

64 Inventario de bienes de María Lorenza Moyano, Mendoza, 30 de diciembre de 1848. AHM, Carpeta Documento Folios 33, 47 y 51.

65 Inventario y tasación de bienes de Juan Videla. Mendoza, 17 de agosto de 1866. AHM, Carpeta 62, Documento 4, Folios 34 v y 43. 
"en la huerta de árboles 42 cepas de moscatel de bracero, en horcón de algarrobo y encatrado de álamo y sauce, a 5 reales: 26 pesos 2 reales. En el costado del Naciente de la huerta, 4 hileras de cepas moscatel, que corren de Sud a Norte, de bracero con horcones de algarrobo y madera de álamo y sauce, en donde se contaron 111 cepas a 5 reales: 69 pesos 3 reales" 66 .

Con menor frecuencia se usaban las cañas. Uno de los pocos ejemplos fue el de Candelaria Vargas e Ignacio Ferramola (1821), que cultivaban "una viña que contiene 814 cepas de moscatel y uva negra embraceradas a los 4 vientos, con madera de algarrobo, atamizque, varazón de sauce y cañas, que a 6 reales cepa, importa: 610 pesos 4 reales" 67 .

Las viñas de bracero estaban dedicadas, principalmente, al cultivo de la uva moscatel. En Cuyo se cultivaban distintas variedades de esta, de las cuales las más difundidas eran moscatel blanco y moscatel de Alejandría, llamada también, uva de Italia. En total, se registraron 65 unidades productivas dedicadas exclusivamente a cultivar cepas de moscatel, para un total de 18.590 plantas $(72,5 \%)$. En tres viñas se cultivaba moscatel y uva negra, con un total de 2.351 plantas $(9,2 \%)$; en cinco viñedos de bracero solo había uva negra, con 2.027 plantas $(7,9 \%)$; y en seis viñas se cultivaba moscatel con otra uva, sin especificar cuál, con 2.680 cepas $(10,4 \%)$. Mirado desde otro punto de vista, se puede señalar que entre las viñas de moscatel y las de uva negra, el $80 \%$ de los braceros de Mendoza se utilizaban para cultivar exclusivamente una variedad, mientras que en el $20 \%$ restante había cepas mezcladas.

\section{ORDENAMIENTO DE LAS CEPAS: LAS HILERAS}

Como se ha indicado oportunamente, una de las principales críticas de Marianetti y sus sucesores a la viticultura artesanal cuyana era la distribución de las cepas dentro de la viña: en vez de colocarlas en hileras, estaban en muchedumbre o desordenadas, modalidad calificada de "irracional" por los críticos.

En realidad, la irracionalidad sería la inconsistencia entre los hechos y la razón. Sin embargo, la razón durante los tiempos de la viticultura artesanal no planteaba ningún problema para este tipo de distribución de cepas en la viña. Los manuales de agricultura no brindaban mayor importancia al tema. Así, ni Herrera (1513), ni Agustí (1617) ni Sandalio Arias (1856) pusieron énfasis en la necesidad de ordenar las cepas en hileras. Solo se hizo una referencia al tema, al plantear la necesidad de adaptar las viñas a las condiciones del suelo y el clima. En particular, para protegerla del viento se recomendó plantar árboles en línea, a barlovento de la viña, "de modo tal que los vientos más recios y dominantes batiesen la filas por el canto y estas, permitiéndolo las demás circunstancias, en

66 Inventario de bienes de Melchor Molina, Mendoza, 8 de junio de 1831. AHM, Carpeta 32, Documento 11 , Folios 7 v, 8 y 26.

67 Inventario y tasación de bienes de María Candelaria Vargas. Mendoza, 8 de marzo de 1821. AHM, Carpeta 19, Documento 6, Folio 14. 
facha al mediodía o al sudeste para que bañándolas mayor cantidad de calor, madurase mejor su fruto" 68 . Fuera de estos casos, el ordenamiento de las parras dentro de la viña no fue tema central de los manuales españoles. Por lo tanto, dentro de ese marco conceptual, si un viticultor hispanoamericano de los siglos XVII, XVIII o XIX cultivaba sus parras en muchedumbre, no se estaba saliendo de la "racionalidad", como pretendía Marianetti.

La conveniencia de ordenar las cepas en hileras fue una de las banderas de la viticultura moderna francesa. Así lo expresó el manual de Guyot, para el cual, esta modalidad tenía una serie de ventajas significativas:

"Este alineamiento asegura a cada cepa una porción igual de suelo, un aireamiento perfecto, una acción de la luz y del calor solares más completa y más eficaz. Da a los trabajos culturales una gran facilidad y permite cumplirlos más rápidamente y con más regularidad. Facilita la distribución de las tierras y los abonos y permite verificar, con un golpe de vista, si todas las partes y todas las operaciones de la viña están hechas bien o con negligencia. Un propietario es señor de su viñador en una viña en hilera; en la viña en muchedumbre, el viñador es el señor del propietario. La poda, la conducción, los desbrotes, los pinzados, atados, vendimia, mantenimiento y reparación de la viña, todo se hace más rápido y mejor en línea que en muchedumbre; la naturaleza también trabaja mejor: las raíces son más bellas, más abundantes y maduran antes en línea, todas las cosas iguales, además" 69 .

A pesar de esta claridad conceptual, el mismo Guyot admitió que en Francia, supuestamente el país más avanzado del mundo en viticultura, todavía existían viñas desordenadas en muchedumbre. En su recorrido por los viñedos de las destintas regiones, el especialista francés detectó varios casos de "cepas en líneas irregulares o diseminadas sin cuidado"70 y otros en que, "en los cuarteles, las cepas están no solo sin alineación, sino también con irregularidades y lagunas muy frecuentes y extendidas" ${ }^{71}$. Esta situación no solo se daba en las regiones más atrasadas, sino también en las más modernas y paradigmáticas, como la zona de Burdeos y el próspero nordeste de Francia, donde se encontraban las cuidadas viñas de la Champagne, Alsacia, Lorena y el Franco Condado. Claro que buena parte de los viñedos de estas regiones ya exhibían prolijos diseños en hileras. En otras palabras, para la avanzada viticultura tradicional francesa de mediados del siglo XIX, no había un patrón universal sobre la forma de ordenar las parras en un viñedo. Los viticultores estaban en una larga etapa de búsqueda.

Algo parecido ocurría en España. No contamos con un estudio de la envergadura del que hizo Guyot, pero referido a las viñas de la península. Sin embargo, existen rastros que nos pueden ayudar a hacernos una idea al respecto. En efecto, las ordenanzas municipales y los cuadros y representaciones gráficas de las viñas españolas revelan que también allí hubo cierta preocupación por impulsar el ordenamiento de viñas en hileras. Nunca fue un método universal y estandarizado. Al

\footnotetext{
68 Herrera, op. cit., 371.

69 Guyot, op. cit., III, 623.

70 Ibid., I, 26.

71 Ibid., I, 124.
} 
contrario, tal como ocurrió en Francia, los viticultores españoles practicaron distintos modos de cultivo de la vid, entre los cuales se incluía el alineamiento de las cepas en hileras, aunque como opcional y no obligatorio. Estos fueron los criterios que los españoles llevaron a América.

En este marco, la observación de la viticultura cuyana hace ver algo interesante: las viñas se plantaban con frecuencia en hileras. Los escribanos y notarios utilizaban este concepto para describir los viñedos en los inventarios y tasaciones de bienes, el cual también se usaba en testamentos y cartas de dote. La organización de la viña en hileras permitía dimensionarla, ya que bastaba con contar las cepas de una hilera y el número de estas, para conocer la cantidad de plantas. En las fuentes compulsadas se detectaron 41 viticultores cuyas viñas, explícitamente, estaban organizadas en forma de hileras.

La cantidad de cepas por hilera resultaba variable, ya que no existía un número estandarizado: oscilaban entre un mínimo de 25 y un máximo de 150 parras, con un promedio general de 77 cepas por hilada. Había tres modalidades de hileras según su extensión: las pequeñas tenían entre 25 y 49 cepas; las medianas, entre 55 y 82; y las grandes entre 107 y 150. Considerando el total de las viñas organizadas de este modo, un tercio eran pequeñas, otro tercio medianas y el tercio restante grandes.

La información de las fuentes sobre este tema, tanto el número de hileras como la cantidad de plantas de cada una de ellas, resulta limitada. Solo en la mitad de los casos, se entregan ambas indicaciones, mientras que en la mitad restante, el notario solo anotó la cantidad de hileras, no así el número de parras que las conformaban. Para realizar la proyección estimada, se consideró la cantidad de plantas promedio de los casos fehacientemente registrados (77 cepas por hilera), base sobre la cual se realizó el cálculo estimado de viñas cultivadas con este sistema. En total, se detectaron 68.346 plantas para el período colonial y 10.466 para la etapa independiente, con un total de 78.812 cepas cultivadas en hileras.

La presencia de casi 80 mil plantas ordenadas de esta forma demuestra que en la vitivinicultura artesanal de Mendoza y San Juan se utilizaba con frecuencia el sistema de hileras para organizar las viñas. Por lo tanto, esta región no tenía nada que ver con las zonas atrasadas de España e Italia que menciona Benito Marianetti, sino que ya se aplicaban criterios modernos en la forma de plantar las viñas. Los viticultores locales, apoyados en la tradición española, habían avanzado en descubrir y valorar las ventajas del ordenamiento en hileras.

La fecha de los registros también entrega datos de interés. La mayor parte de las cepas identificadas en hileras fue registrada en el siglo XVIII: a este período corresponden 33 registros, con 68.000 plantas, mientras que en el período independiente se identificaron 8 viticultores con este sistema, para cultivar 10.500 plantas. Así, el período colonial concentró el $80 \%$ de los viticultores que cultivaban con hileras y el $86 \%$ de las viñas con este sistema. Este elemento genera una serie de interrogantes, difíciles de contestar con los datos actualmente disponibles. La caída de registros de hileras en los dos primeros tercios del siglo XIX puede deberse a dos razones: una es que la organización en hileras haya estado estandarizada, motivo por el cual ya no se consideraba necesario mencionarla en los documentos; 
la otra es que haya habido un retroceso técnico, dado que después de la Independencia, en el contexto de las guerras civiles, se pudo sufrir una pérdida de las formas de cultivar la viña que se habían alcanzado durante la pax hispanica. Por el momento, ambas interpretaciones pueden ser correctas.

\section{LOS PARRALES Y SU EVOLUCiÓN, DE EUROPA A CUYO}

Los parrales también fueron una modalidad interesante de cultivo de la vid en Cuyo. Desde el punto de vista comercial, su importancia era menor a la de las viñas, lugar donde se cultivaba el $97 \%$ de las cepas, mientras que los parrales apenas representaban el $3 \%$ restante. De todos modos, el parral era muy importante desde el punto de vista social, porque más que una unidad de producción económica era un auténtico espacio de sociabilidad, como una ampliación de la casa, un salón al aire libre con un denso techo vegetal durante el verano.

El cultivo de la vid en parrales ha sido un tema recurrente en la viticultura tradicional. Hacia fines de la Edad Media, los españoles se interesaron por los parrales y lo expresaron de manera explícita, lo que se reflejó en ordenanzas municipales y manuales agrícolas. Así, las ordenanzas municipales de Orduña de 1499 establecieron normas relativas al sistema de conducción de viñedo en parrales; mientras que en Valmaseda, a través de las ordenanzas a la aljama de la villa, se impulsaron regulaciones sobre el viñedo, incluyendo los sistemas de conducción ${ }^{72}$. El primer manual español de agricultura definía como parral a la "vid que está armada sobre madera o árbol"73. Por lo general, se recomendaba el uso del parral en terrenos húmedos, para proteger la uva de la podredumbre. A partir de sus observaciones, el autor formuló las siguientes recomendaciones:

"Estos parrales ponen en Italia en una de dos maneras, que o son en tierras de pan, o no. Si son en tierras de pan ha de haber en ancho de árbol a árbol 40 pies, porque el sol pueda dar en lo sembrado de lleno en lleno. Y si no han de ser tierras de pan basten de espacio 20 pies. Y para las que han de ser de pan del un cabo ha de ser del anchor que dije el liño, y del otro no más de 15 o 20 pies a los árboles, porque de uno a otro se abracen las cepas con los árboles como quien va en danza. Para tierra así armadas si la tierra es muy húmeda, son buenos álamos blancos o sauces porque estos árboles se crían mucho en el humor, y sin son tierras enjutas son mejores álamos negros o fresnos. En árboles de fruta no es mi consejo ponerlas, porque los echa mucho a perder. Ha de tener el árbol tanta altura en el tronco cuanto una estatura de un hombre y allí en cabo del pie tenga dos o tres horcas sobre que la vid acode y esté reposada, porque no esté colgada, que recibe gran perjuicio con la atadura. Y procuren al árbol dejarle en las ramas muchas horcas, para que en ellas se asgan los sarmientos. Y las ramas altas, desvariadas, luengas, hanselas de desmochar porque no suban muy alto, que lo uno asombran y aun son peligrosas para subir a podar y a vendimiar, que más vale que los sarmientos

72 Ana María Rivera Medina, "Vid, viñedos y vino en Sefarad: Cultivo, elaboración y comercio de un vino diferenciador”, en Espacio, tiempo y forma 20, Madrid, 2007, 199-233.

73 Herrera, op . cit., 365 
cuelguen desde alto con el fruto, que no que estén donde sean penosos y aun peligrosos de alcanzar como dice el Crecentino" 74 .

Por su parte, en España también se usaban parrales apoyados en árboles vivos, pero de otras especies, debido a la tradición que aportaron los árabes. La costumbre de usar árboles como sostén de los parrales se extendió a lo largo de todo el período de viticultura tradicional en Europa. A mediados del siglo XIX, cuando ya estaba terminando el ciclo de la viticultura tradicional, todavía se usaba este sistema en Francia ${ }^{75}$. Esta costumbre también se trasladó a América en general y a Cuyo en particular, como se examina más adelante.

El uso de parrales abrió paso para el desarrollo de técnicas de conservación de la fruta, sobre todo porque mediante un aislamiento de la humedad, hacían posible mantener las uvas hasta el invierno. La propuesta no se formuló en el libro de Herrera, sino un siglo después, en el manual de Agustí. A partir de sus experiencias y observaciones, el religioso recomendaba:

\begin{abstract}
"Conservaréis en las vidas de los parrales las uvas hasta la primavera haciendo en tierra un hoyo cerca de la vid, en lugar de sombra, de profundidad de tres pies, y dos de ancho, y en dicho hoyo pondréis un poco de arena, y plantaréis en él algunos troncos o palos y bajareis la vid con las uvas, y las pondréis en dicho hoyo envueltas con dichos palos atándolas porque no se muevan, cuidando que las uvas no se toquen unas con otras; y cuando ello se hiciere, sea día claro y enjunto y que no sean demasiado maduras y sean enteras; después henchiréis todo el hoyo de arena, para que el sol, aire ni lluvia las toque. Y allí con la virtud de la vid, y con el frescor de la arena, se mantendrán frescas y enteras hasta la primavera. Conservarse han todo el invierno, si las cogéis en luna menguante, en día sereno y en la mañana"76.
\end{abstract}

La propuesta del religioso resulta de interés por las proyecciones. Además de valorar los parrales como medio de sostén para la vid, los utilizó como puerta de entrada al desarrollo de la industria conservera, proceso complejo debido a la rápida descomposición que sufre la uva. Con sus recomendaciones, el clérigo planteó un horizonte que, con el tiempo, daría lugar a un interesante desarrollo agroindustrial.

Naturalmente, las viñas bajas eran el método predominante entre los viticultores de la península, pero los parrales lograron hacerse su espacio. Los registros documentales de parrales en España se remontan a comienzos del siglo XII y corresponden a la región de La Rioja, en Nájera, hacia 1171, se cultivaba un parral en la glera de San Julián, junto a varios parrales del rey y en 1293 se detectaron otros parrales en Algeta. Posteriormente, entre los siglos XIII y XIV, se celebraron varios contratos en los cuales se encargaba a un viticultor convertir viñas en parrales.

Como sostén se usaba con frecuencia el sauce. El concepto de parral se asociaba con el de elevación y se usaba la expresión "parral alzado"77. El desarrollo de

$74 \quad$ Ibid., 366 .

75 Guyot, op. cit., I, 7.

76 Agustí, op . cit., 201-202.

77 Fernando Andrés Barrios, “Algunas noticias contenidas en la documentación medieval riojana publicadas hasta la fecha, sobre los tipos de vinos y sus métodos y técnicas de elaboración, en la 
los parrales alcanzó niveles preferenciales en ciertas partes de España, como por ejemplo, en Bilbao.

"Los viticultores, conocedores del clima de la Villa, optaron por el sistema de emparrado o parral y no por el de viña de arrastre o de baja altura, más propia de las regiones de secano. El parral, en este caso, proporciona el aislamiento necesario entre la canopia [follaje] y la base del tronco; además aquella tenía una mayor exposición al sol, dado que el emparrado permite la extensión de las ramas, un mayor desarrollo de los pámpanos, y menor contacto con la humedad del suelo"78.

El cultivo de las cepas en parrales fue una costumbre no solo de los cristianos, sino también de las colectividades judías.

"Según el listado elaborado por el Concejo de los bienes de la comunidad hebrea de Valmaseda, existían en zona periurbana cuatro viñedos catalogados como parrales, tres de ellos propiedad del Rabí Samuel y el cuarto en la cantera del Santo Ruego. Los parrales abundaron en la zona del Duero, donde se utilizaron para intensificar el cultivo. Esta modalidad propició que muchas comunidades judiegas incluyeran la 'atada' como una de las tareas propias del cultivo y a la que se dedicaban en los meses de invierno y primavera"79.

El caso de estos judíos permite intuir la valoración que, en general, los viticultores españoles brindaron a los parrales.

Los viticultores cuyanos también le dieron importancia a este sistema. Al igual que las viñas de bracero, los parrales se apoyaban en horcones, que eran tan sólidos como los de aquellos, pero se caracterizaban por ser más altos. Ellos sostenían las cepas, a la vez que los sarmientos eran conducidos por medio de encatrados y embracerados.

El uso de árboles vivos para sostener los parrales fue una práctica regional, la que, al igual que en Italia, España y Francia, también se usó en Cuyo. Así, por ejemplo, don Juan Isidro Maza cultivó "un parral con trece cepas y tres horcones de algarrobo labrados de 3 varas de alto, encatrado y soleras de barejones y varillaje de álamo, todo en buen estado, y una morera sirviendo de horcón, tasado en 22 pesos" $"$. De todos modos, el uso de árboles vivos como sostén de los parrales no fue una práctica habitual entre los cuyanos, ya que para esos fines, ellos preferían usar horcones.

Los parrales encatrados eran parte de la casa. Formaban un ambiente complementario, como una sala con techo vegetal, que protegía a los comensales en el verano,

Rioja, en la Edad Media”, en Maldonado Rosso, Javier y Ramos Santana, Alberto (editores), Actas del

I Encuentro de Historiadores de la Vitivinicultura española, Puerto de Santa María, Ayuntamiento del Puerto de Santa María, 2000, 85.

78 Ana María Rivera Medina, "Producción local, abastecimiento urbano y regulación municipal: El marco legal del vino en Bilbao (siglos XIV-XVI)", en Espacio, tiempo y forma 19, Madrid, 2007, 233-264.

79 Rivera Medina, "Vid, viñedos y vino en Sefarad...", op. cit., 199-233.

80 Inventario de bienes de Juan Isidro Maza, realizado por el perito Ignacio María Palacio, Mendoza, 10 de noviembre de 1853. AHM, Carpeta 36, Documento 2, Folio 28. 
pero dejaba llegar el calor del sol en invierno. Allí se celebraban reuniones familiares y se recibía a los visitantes, se tomaba mate y se comía, se jugaba cartas y se realizaban transacciones comerciales. Con frecuencia, debajo del parral encatrado había una mesa de múltiples usos, sobre la cual el mate invitaba a la tertulia. A su alrededor, el viticultor alternaba con familiares y amigos, proveedores y clientes, arrieros y troperos, pulperos y peones. Debajo del parral se hablaba de las labores agrícolas, se compartían noticias con los viajeros, se practicaba la amistad y se construía familia. Junto con la pulpería, el parral encatrado ocupaba un lugar central como espacio de sociabilidad en las provincias cuyanas y chilenas en general.

La importancia del parral como espacio social se ha reflejado también en la literatura cuyana, la cual muestra recurrentemente el parral como espacio social, particularmente en la obra de Juan Draghi Lucero. "Pasaron todos al gran patio donde se lucían las mesas bajo el parral", relata uno de sus cuentos, "y fueron servidos los mejores potajes y tentaciones. Todo era una alegría y un cambiar de brindis y pasarse vasos y copas en un encadenamiento de compromisos" $"$. En otra obra, el autor se apoya en la imagen del parral para desplegar un poema de amor: "En el huerto que cuidamos/ dulce esposa, cenaremos/ bajo la parra hogareña/ con horneado pan moreno./ Aceite de viejo olivo/ vino de nuestro lagar/; blanco mantel en la mesa/ bendiciendo, mancharán" 82 . La presencia del parral en la literatura es compartida también por autores chilenos, como Alberto Blest Gana. En El ideal de un calavera (1863), el parral es un lugar central, donde se encuentran los protagonistas de una pasión intensa e imposible, que determina el devenir de toda la novela ${ }^{83}$.

El encatrado era la construcción de un catre de madera, que se usaba en distintas actividades. De acuerdo al Diccionario del Habla de los Argentinos, este término designa el "armazón con forma de catre que se usa para sostener vides u otras plantas" 84 . Sin embargo, además de esa función, el encatrado se utilizaba también para la construcción de los edificios de la hacienda. Así, por ejemplo, en la hacienda de don José Albino Gutiérrez (1831) había "un granero en bóveda con cimiento doble de piedra, murallas de adobe, cuatro tirantillos, pico del recipiente enlajado, y el del granero encatrado de tirantes rollizos con ladrillo" 85 . De este documento se desprende que el concepto de "encatrado" se usaba para dar cuenta de construcciones de madera con cierto grado de solidez. En este caso, la madera estaba formada por troncos gruesos y firmes (rollizos), con ladrillos, que representaban un material de construcción todavía escaso para la época.

La literatura especializada en viticultura de comienzos del siglo XX señalaba que todavía existía este sistema en Argentina. En ese sentido, resultan interesantes las observaciones del italiano Galanti, el cual, con los conocimientos adquiridos en su país de origen, recorrió las viñas argentinas y elaboró interesantes observacio-

81 Alberto Draghi Lucero, El loro adivino, Buenos Aires, Troquel, 1965, 255.

82 Juan Draghi Lucero, Antología Poética, Mendoza, Ediciones La Sopaipilla, 1990, 57.

83 Alberto Blest Gana, El ideal de un calavera [1863], Santiago, Editorial Andrés Bello, 1999.

84 Academia Argentina de la Lengua, Diccionario del habla de los argentinos, Buenos Aires, Espasa, 2003, 290 .

85 Inventario de bienes de don José Albino Gutiérrez, Mendoza, 19 de octubre de 1831. AHM, Testamentaria José Albino Gutiérrez, Carpeta $\mathrm{N}^{\mathrm{o}} 23$, Documento $\mathrm{N}^{\mathrm{o}} 1$, Folio $50 \mathrm{v}$. 
nes, entre ellas, de los sistemas de conducción mediante parrales encatrados. El autor los detectó, fundamentalmente, en las provincias de Salta y en San Juan, y los describió en los siguientes términos:

"Una vez escogido el terreno, se traían a él grandes troncos, generalmente de algarrobo, para que sirvieran de horcones. Estos troncos miden entre 2,50 y 3,50 metros de alto y alrededor de 50 centímetros de diámetro, no bajando este nunca de 30 centímetros. Con grandes dificultades se enterraba este horcón unos 50 centímetros; pero como los troncos variaban de longitud, de ahí resulta lo que hoy se nota, es decir, que el emparrado forma líneas ondulantes en algunas partes de tres metros de alto y en otras de dos metros, llegando en algunos puntos a hacerse hoy la cosecha con los hombros agachados pues el parral no tiene más de 1,50 metros de altura" 86 .

En la viticultura cuyana, el parral encatrado se apoyaba en horcones de algarrobo, sobre los cuales se construía el catre de madera que ofrecía una superficie sólida para el crecimiento de la cepa. Don Francisco Riveros (1868) tenía "doce parritas nuevas frutales encatradas y con 20 horcones chicos de algarrobo", además de "17 parras encatradas y embraceradas y con malos horcones" 87 . Con la introducción de nuevas especies forestales, como el álamo, se comenzó a utilizar esta madera que, al ser más blanda que el algarrobo, permitía mayor trabajo. Así, por ejemplo, don José María Videla (1863) cultivaba "un parral encatrado compuesto de 206 cepas, con sus correspondientes pilares de álamo labrados, canes y viguetas y soleras de la misma madera y bases de olivo: 500 pesos" $" 88$.

El parral encatrado implicaba mayor valor agregado a la viña. Era lo más intensivo dentro de una actividad agrícola intensiva como la viña y por eso mismo, era poco frecuente, pero de notable valoración. Por ejemplo, en las haciendas de don José María Videla (1863), la mayor parte de las viñas (19 mil plantas) no tenían este sistema de conducción y su valor de mercado era de 18 centavos por parra, en cambio, el que sí lo tenía se cotizó a 2 pesos 42 centavos por cepa ${ }^{89}$. Por su parte, el parral encatrado de don José Albino Gutiérrez, con solo seis cepas, se cotizó a 15 pesos, debido a sus horcones de cuatro varas de alto ${ }^{90}$.

En algunos casos se construyeron parrales grandes. Juan José Lemos (1843) cultivó "un parral de moscatel con 1.312 cepas embraceradas y con horcones de varias maderas a $2 \frac{1}{2}$ reales cada una cepa, importan: 410 pesos" 91 . Dionisio Sarmiento (1844) tenía un parral de 344 cepas y don Eusebio Ríos (1865) cultivaba “332 parras de moscatel, entre estas algunas de uva mollar, entre grandes, media-

86 Galanti, op. cit., 37.

87 Cesión de bienes a favor de sus acreedores de don Francisco Riveros. San Juan, 4 de julio de 1868. APJSJ, Caja 29, Estante 2, Expediente 244, Folio 24.

88 Inventario de bienes de José María Videla, Mendoza, 4 de setiembre de 1863. AHM, Carpeta 62, Documento 1, Folio 37 v.

89 Testamentaria de José María Videla, Mendoza, 4 de setiembre de 1863. AHM, Carpeta 62, Documento 1 , folios 37,41 y $42 \mathrm{v}$.

90 Inventario de bienes de don José Albino Gutierrez, Mendoza, 19 de octubre de 1831. AHM, Testamentaria José Albino Gutiérrez, Carpeta $\mathrm{N}^{\mathrm{o}} 23$, Documento $\mathrm{N}^{\mathrm{o}}$ 1, Folio 50v.

91 Inventario, tasación y división de bienes de Juan José Lemos, Mendoza, 4 de agosto de 1843. AHM, Carpeta 30, Documento 14, Folio 28. 
nas y chicas, todos con sus horcones y encatrados; tasó unas con otras en 60 centavos; importan 199 pesos 20 centavos"92. De todos modos, eran casos excepcionales.

En general, los parrales encatrados eran pequeños y tenían pocas cepas. Menos del $10 \%$ de estos tenían más de dos centenares de cepas, como se ha visto en los casos de Juan José Lemos (1.312 parras), Dionisio Sarmiento (344), Eusebio Ríos (332) y José María Videla (206). Otro 10\% de los parrales tenía entre 100 y 200 cepas y un $15 \%$ oscilaba entre 15 y 65 plantas, pero la mayoría de los parrales tenía entre dos y diez cepas. Entre ellos Toribio Santibáñez (1775), quien tenía "un parral con tres plantas y nueve horcones de algarrobo y otro con tres plantas y encatrado con quince horcones"93; y Pedro Sarmiento (1779) cultivaba "un parral de moscatel en su encatrado de palos y dos horcones y cuatro horcones más"94.

Evidentemente, la importancia de los parrales encatrados no era tanto económica como social y cultural: los viticultores cuyanos apreciaban el parral encatrado, pues era un símbolo de laboriosidad y capacidad de manejo de la viña. El $90 \%$ de las propiedades vitivinícolas tenían su parral encatrado junto a la casa. De todos modos, el elevado costo de materiales y trabajo limitaban la difusión del sistema.

El cruce entre tipo de cepaje y modo de cultivo entrega también datos de interés, sobre todo porque la cultura vitícola española construyó una larga tradición en este sentido. En efecto, el primer manual de agricultura español, planteó la conveniencia de brindar especial atención y cuidado al moscatel, especialmente porque "la uva, por ser de buen sabor, suelenla mucho hurtar, por lo tanto conviene que quien de ello tiene buena pro en su viña que lo guarde bien, que no bastan bardales ni paredes bien altas para defenderlo de manos de golosos"95. Al buscarse lugares altos y fáciles de controlar, el espacio natural que hallaron los viticultores cuyanos para cultivar sus cepas de moscatel fue, precisamente, en los parrales encatrados que estaban junto a las casas.

Los viticultores cuyanos tendían a cultivar el moscatel en parrales. Como muestra la evidencia documental, el $88 \%$ de las cepas cultivadas en los parrales era exclusivamente moscatel, mientras que el resto era moscatel mezclado con otras variedades, o bien uva negra, blanca y otras layas.

La presencia hegemónica del moscatel en los parrales cuyanos fue constatada, años después, en las observaciones que hizo Storni en terreno. En efecto, de acuerdo a este autor, la cepa que él llamaba moscatel blanco

"ha sido conducido siempre en parrales, formados en tipo antiguo, de encatrados de madera y caña de Castilla, mientras que en las plantaciones más recientes, son del sistema valenciano, con alambres. Raramente se encuentra este cepaje en espaldera, en

92 Cesión de bienes de don Eusebio Ríos, San Juan 21 de abril de 1865. APJSJ, Caja 28, Estante 2, Expediente 236, Folio $17 \mathrm{v}$.

93 Inventario de bienes de Toribio Santibáñez, San Juan, 15 de setiembre de 1775. APJSJ, Libro Joseph Sebastián de Castro, Protocolo 1775, Folio 162 v.

94 Inventario de bienes de don Pedro Sarmiento, San Juan, 6 de septiembre de 1779. APJSJ, Libro Joseph Sebastián de Castro, Protocolo 1779, Folio 155 v.

95 Herrera, op . cit., 316. 
algunos distritos de la provincia de Mendoza lo he encontrado cultivado de esta forma, hasta con tres alambres" $" 96$.

Los mejores parrales de la viticultura tradicional en el siglo XIX fueron los de don Manuel José García (1838), que se caracterizaban por tener horcones de algarrobo a medio labrar y de gran altura ( $3 \frac{1}{2} 2$ varas). Este era un sistema de alto costo (solo los horcones valían 5 reales), pero permitía una amplitud significativa, tanto para el espacio del parral, en cuanto espacio social, como para que el sol pudiera capturar la planta. Cada cepa, con este nivel de trabajo, se llegó a valuar en siete reales, precio superior a todas las demás parras. Los tasadores describieron estos parrales en los siguientes términos:

“ítem 88 cepas de moscatel emparronadas con un horcón de algarrobo a medio labrar y de $3 \frac{1}{2}$ varas de alto, cada uno a 7 reales: 77 pesos; ítem 5 horcones sin cepa al pie que hay en dicho parral, de igual calidad a los anteriores, a 5 reales; ítem 55 cepas también de moscatel con horcones ordinarios de varias maderas a 2 reales: 13 pesos 6 centavos" ${ }^{97}$.

\section{FORMAS DE PODAR LA VIÑA}

La forma de podar la viña era bastante parecida en Francia, España y Cuyo. En todas estas regiones se seleccionaba la cantidad de brazos que se dejaban crecer en cada cepa y el resto, es decir, los sarmientos estériles, se recortaban. La fuerza de la planta se concentraba en los brazos seleccionados, sobre los cuales se realizaba el trabajo cultural durante todo el año. El manual de Herrera mencionaba, tempranamente, la poda de tres puntas.

En el caso de Francia, Guyot destacó que los viticultores franceses tendían a dejar dos sarmientos a la cepa en los dos primeros años de vida y posteriormente, al tercer o cuarto año, dejaban crecer un tercero. Los tres brazos crecían en primavera y verano, para culminar con una longitud de cinco a seis metros. En esas condiciones se llegaba a la producción de la uva y su cosecha en otoño, después de lo cual se realizaba la poda seca o poda de invierno. "En la poda de invierno, esos sarmientos entrelazados unos en los otros, son replegados en ellos mismos y unidos en atados que se vende a los panaderos para calentar el fuego; no nos podemos figurar un lujo parecido de vegetación, o no hemos tenido la ocasión de observarlo"98.

La poda en los viñedos cuyanos tenía bastantes aspectos en común, como se desprende de los registros del padre Godoy. De acuerdo a sus observaciones, en Mendoza

\footnotetext{
96 Carlos D. Storni, Descripción de vidueños que se cultivan en la Argentina desde la época colonial, Córdoba, Tamburini, 1927, 30-31.

97 Inventario, tasación y división de bienes de Manuel José García. Mendoza, 15 de diciembre de 1838. AHM, Carpeta 24, Documento 1, ítem 125-127.

98 Guyot, op. cit., I, 81.
} 


\begin{abstract}
"se hace la poda más arreglada a las leyes que prescribe la agricultura: se corta a la cepa todo sarmiento inútil e infructífero, solo se le dejan aquellos que muestran más robustez y vigor y estos no pasan de tres o cuatro. Al sarmiento cortado fructífero no se le dejan sino dos o tres yemas. Lo demás se corta. En San Juan se dejan más sarmientos a la cepa y más yemas al sarmiento. De esta conducta dan la razón las gentes de este país, diciendo que es necesario hacerlo así, porque pueden los brotes resistir a la fuerza o al impulso de los vientos que son allí fuertes y frecuentes y que cuando se venga a quebrar y así a perderse uno u otro, siempre le queda a la cepa dónde echar nuevo sarmiento y nuevo fruto en él. Tal vez esta razón tendrá más fuerza en la experiencia que en las leyes de cultivo" 99 .
\end{abstract}

La descripción del padre Godoy es uno de los pocos testimonios directos, de la época colonial, sobre las tareas culturales en las viñas cuyanas. El conocimiento del tema se profundizó en el estudio de Rivera Medina sobre la familia Del Carril de San Juan. A partir de una serie de documentos, la autora reconstruyó las tareas culturales en los siguientes términos:

\begin{abstract}
"Se regaba en mayo, agosto, octubre, noviembre, diciembre y enero: para ello, en el mes de junio se limpiaban las acequias, tanto la toma a la entrada de la viña como las situadas en los cuarteles. Por estas fechas también se sustituían los rodrigones antiguos por otros nuevos. En agosto se solía abonar con excrementos de los animales. En setiembre se replantaban las fallas (de haberlas) y en los meses de verano se mantenía la canopia [follaje] mediante el despampanado" 100 .
\end{abstract}

El trabajo cultural de la cepa variaba según los sistemas de sostén y conducción. Las cepas de cabeza se podaban a pitón; sus sarmientos eran muy cortos y no se ataban, sencillamente porque no había dónde atarlos. En cambio las capas embraceradas o las de parrales encatrados sí podían tener sarmientos más largos, los cuales debían atarse. Este incremento del trabajo cultural guardaba relación con el valor de las plantas: no olvidemos que las cepas de bracero solían tasarse al doble del precio de las de cabeza.

La reconstrucción historiográfica de Rivera Medina complementa y consolida el testimonio del padre Godoy, realizada un cuarto de mileno antes. Para mantener las cepas con escaso número de brazos, los cuyanos realizaban su trabajo de poda todos los años. Se practicaba la poda seca o poda de invierno, es decir, se cortaban tiempo después de la cosecha, en pleno invierno, cuando los sarmientos estaban largos y secos. Al parecer se seguían las recomendaciones de Herrera (1513), el cual sugería la poda de tres puntas. Los recortes se usaban para calentar los hornos de botijería, las calderas de los alambiques y las fraguas de los herreros. Posteriormente se realizaba la poda verde, poda de verano que se usaba en Francia y España

99 Carta del St. Abate N. Americano al S. Abate N. Genovés, 6 de julio de 1787. En: Fuente Americana de la Historia Argentina. Descripción de la provincia de Cuyo. Cartas de los jesuitas mendocinos, Mendoza, Biblioteca de la Junta de Estudios Históricos, 1940, 44.

100 Ana María Rivera Medina, Vitivinicultura y Patrimonio en los Vásquez del Carril (1731-1815) San Juan, Argentina, San Juan, Editorial Fundación de la Universidad de San Juan, 2007, 118. 
para despampanar la viña ${ }^{101}$. Asimismo, el texto del jesuita entrega una discriminación entre las prácticas culturales de Mendoza y San Juan. En esta última, la fuerza del viento zonda llevaba a los viticultores a mantener mayor cantidad de brazos en sus cepas, dada la frecuencia con que se caían y rompían los sarmientos, los que se ataban con mimbre en Europa y con totora en Cuyo. Más allá de estas explicaciones, lo importante es señalar cómo, desde el siglo XVIII, hubo en las dos ciudades cuyanas una tradición del trabajo cultural intensivo durante todo el año en la viña. Más allá de los matices, tanto los mendocinos como los sanjuaninos lograron poner en marcha un método disciplinado y riguroso de atención de las cepas, con vistas a optimizar sus cosechas.

\section{CONCLUSIÓN}

Lejos del perfil descuidado e irracional que le atribuía la literatura especializada hasta ahora, la viticultura artesanal de Cuyo se caracterizó por el cuidado y la delicadeza en el trato de los distintos viduños, que se cultivaban mediante un intenso trabajo cultural durante todo el año. A pesar de no disponer de alambre para la conducción de las cepas, los protagonistas de la viticultura tradicional lograron aprovechar los medios entonces existentes para resolver los problemas prácticos que planteaba la vid. En permanente contacto con los vecinos de Chile occidental, los chilenos de Mendoza y San Juan buscaron y encontraron los caminos adecuados para llevar adelante una viticultura de cuidado. Esta modalidad se hizo visible desde fines del siglo XVIII hasta mediados del XIX, pero fue el resultado de un largo proceso histórico, que abarcó los trescientos años de historia, a partir de la llegada de los españoles a las desérticas tierras cuyanas.

Los viticultores cuyanos emplearon distintos modos y criterios para cultivar la viña. Con frecuencia, las parras se ordenaban en filas o hileras dentro del viñedo, para facilitar los trabajos culturales. La evidencia documental ha permitido dar por superada las hipótesis anteriores. Algo parecido ocurre con las formas de sostén y conducción.

Las cepas de la viticultura tradicional cuyana se cultivaban en viña $(96,5 \%)$ o en parral encatrado $(3,5 \%)$. A su vez, dentro de las viñas se utilizaban dos prácticas culturales: a) las cepas de vaso o "de cabeza", para usar la expresión americana, comprendían el cerca del $75 \%$ del total de las viñas; y b) las cepas embraceradas representaban aproximadamente el $25 \%$ restante. En las viñas se realizaba el cultivo con fines comerciales, mientras que el parral era parte de la casa y se utilizaba como sala con techo natural al aire libre, por lo que era un espacio social importante en la vida cotidiana.

En los dos primeros tercios del siglo XIX, las viñas de Mendoza eran cultivadas con cepas de cabeza y de bracero. El sistema más difundido era el primero, con el

101 Despampanar: "conjunto de operaciones de pinceado, recorte, desbrote y deshoje; en una palabra, todas las operaciones que tienen por objeto recortas todo o parte de los pámpanos" (Guyot, op. cit., I, 86). 
cual se cultivaban 128 mil plantas (76\%), mientras que el bracero se usaba para 39 mil cepas (24\%). Así, cada cuatro plantas había tres cepas de cabeza y una de bracero. En San Juan se mantenía una proporción parecida, con una tendencia un poco menor hacia la conducción: las cepas de bracero representaban el $22 \%$ de las viñas.

Desde el punto de vista del valor de mercado, las cepas embraceradas se encontraban en un punto intermedio entre las parras comunes y las encatradas. El caso de don José María Videla es representativo: las cepas comunes valían 18 centavos, las cepas de parral encatrado 2 pesos 40 centavos y las embraceradas se valuaban en 31 centavos cada planta ${ }^{102}$.

El cruce del tipo de cultivo con la variedad de uva es interesante. En las viñas de Mendoza, por lo general, la uva negra se cultivaba en cepas de cabeza y el moscatel en bracero. En efecto, el $98 \%$ de las cepas de cabeza eran de uva negra y solo el $2 \%$ restante era moscatel. En cambio, en las viñas de bracero, las correlaciones se invertían: el $72,4 \%$ era moscatel y el $7,9 \%$ uva negra. El resto eran combinaciones y mezclas: $9,2 \%$ de moscatel y uva negra, $10,4 \%$ de moscatel y uva sin especificar. Algo parecido ocurría en los parrales. Estos cultivaban $88 \%$ de moscatel y el resto de moscatel mezclado con otras variedades y uva negra, blanca y otras layas.

Observado desde la perspectiva de las variedades, el enfoque también permite ver los contrastes. La uva negra comprendía el $98 \%$ de las cepas de cabeza y el $8 \%$ de las viñas de bracero; en cambio no existían parrales dedicados a cultivar, exclusivamente, este tipo de uva. Por su parte, el moscatel comprendía el $2 \%$ de las cepas de cabeza, el $72 \%$ de los braceros y el $88 \%$ de los parrales. Saliendo en los cultivos especializados en una sola variedad, para entrar en las mezclas, resulta que estas no estaban presentes en las cepas de cabeza, pero comprendían el $20 \%$ de los braceros y el $12 \%$ de los parrales.

La madera constituía una parte importante de las viñas, ya que con ella se fabricaban los tutores, horcones y varazones. Los tutores se usaban en las cepas de cabeza y eran, por lo general, ramas de algarrobo. Por su parte, las viñas de bracero tenían horcones y varazones. Habitualmente, los horcones eran de algarrobo (más del $80 \%$ de los casos), pero también se usaban otras maderas, como retamo y frutales (perales y guindos), mientras que el varazón se hacía con varillas de sauce o álamo. Ambas modalidades estaban presentes casi en igual proporción, con ligera supremacía del sauce. En casos excepcionales se usaban cañas.

En el cruce entre la intensidad de trabajo cultural y el tamaño de la propiedad se descubre una proporción inversa. Los propietarios mayores, con capital superior a los 30 mil pesos, tenían sus viñas con altos porcentajes de cepa de cabeza (78\%) y menor cantidad de cepas de bracero $(22 \%)$. Por el contrario, los pequeños propietarios (capital inferior a 10 mil pesos) realizaban más trabajo en sus viñas para añadirles valor: sus cepas de cabeza comprendían el 63\%, mientras que las cepas

102 Testamentaria de José María Videla, Mendoza, 4 de setiembre de 1863. AHM, Carpeta 62, Documento 1 , folios $37,41,42 \mathrm{v}$ y $44 \mathrm{v}$. 
de bracero llegaban al 34\%. En términos proporcionales, los viticultores pequeños de Mendoza lograron embracerar un 50\% más de cepas que los grandes.

El trabajo intenso, sostenido durante todo el año, para cultivar la viña, generó un modelo de agricultura intensiva, orientada a la agroindustria. Este modo de producción contribuyó a promover el desarrollo de la pequeña propiedad, con fuertes pautas de movilidad social. A diferencia de lo ocurrido en la mayor parte de América Latina, donde predominaron los latifundios y las oligarquías terratenientes, en los espacios donde predominó la viticultura como eje de la actividad económica (Cuyo, Chile), se constituyeron sociedades económicamente más integradas y políticamente más estables. El camino se trazó mediante el trabajo intensivo al pie de la viña, sostenido durante siglos. Sobre esta base se iba a poner en marcha, a partir de fines del siglo XIX, la vitivinicultura moderna en la región. 